\title{
Promising quaternary chalcogenides as high-band-gap semiconductors for tandem photoelectrochemical water splitting devices: A computational screening approach
}

Pandey, Mohnish; Jacobsen, Karsten Wedel

Published in:

Physical Review Materials

Link to article, DOI:

10.1103/PhysRevMaterials.2.105402

Publication date:

2018

Document Version

Publisher's PDF, also known as Version of record

Link back to DTU Orbit

Citation (APA):

Pandey, M., \& Jacobsen, K. W. (2018). Promising quaternary chalcogenides as high-band-gap semiconductors for tandem photoelectrochemical water splitting devices: A computational screening approach. Physical Review Materials, 2(10), [105402]. https://doi.org/10.1103/PhysRevMaterials.2.105402

\section{General rights}

Copyright and moral rights for the publications made accessible in the public portal are retained by the authors and/or other copyright owners and it is a condition of accessing publications that users recognise and abide by the legal requirements associated with these rights.

- Users may download and print one copy of any publication from the public portal for the purpose of private study or research.

- You may not further distribute the material or use it for any profit-making activity or commercial gain

- You may freely distribute the URL identifying the publication in the public portal 


\title{
Promising quaternary chalcogenides as high-band-gap semiconductors for tandem photoelectrochemical water splitting devices: A computational screening approach
}

\author{
Mohnish Pandey* and Karsten W. Jacobsen ${ }^{\dagger}$ \\ CAMD, Department of Physics, Technical University of Denmark, DK-2800 Kongens Lyngby, Denmark
}

(Received 29 March 2018; published 9 October 2018)

\begin{abstract}
Significantly high efficiency of the photoelectrochemical (PEC) water splitting process can be achieved by using two semiconductors in a tandem device. The smaller band gap (SBG) material in the device has a band gap of $\sim 1 \mathrm{eV}$, whereas the larger band gap (LBG) material has a band gap of $\sim 2 \mathrm{eV}$. However, a very limited number of LBG semiconductors have been explored and here we investigate systematically the quaternary chalcogenides of $A_{2} B C X_{4}$ type. We calculate the properties of the materials in six different crystal structures. Based on the criteria of thermodynamic stability, band gap, and good charge transport properties, we find a handful of potential LBG candidates from a pool of 1368 materials. Additionally, by extrapolating our analyses we also find a few SBG semiconductors, some of which are already known, e.g., CZTS/AgZTSe. This consolidates our approach for the LBG semiconductors and therefore invites experimental investigation of the candidates identified as efficient LBG semiconductors for the tandem devices.
\end{abstract}

DOI: 10.1103/PhysRevMaterials.2.105402

\section{INTRODUCTION}

Efficient and economically viable harvesting of solar energy is one of the biggest technological challenges in energy research. A large amount of effort has gone into finding materials which can carry out the conversion of solar energy to different usable forms of energy, for example, chemical fuels, electricity, and thermal energy [1-6]. However, the development in different routes for the solar energy conversion has been uneven and some pathways have seen relatively less improvements than others. For example, the efficiency of single-junction photovoltaic (PV) devices has increased remarkably from $\sim 1 \%$ to $\sim 22.1 \%$ in the past seven decades $[7,8]$. However, the durability of record efficiency solar cells is still an issue and several attempts are being made to increase the stability of these PV devices [9]. Contrary to the impressive development in the PV devices, the improvement of photoelectrochemical (PEC) devices to generate chemical fuels, especially hydrogen, has not been very significant. Until recently, most of the effort has gone into development of single-photon PEC devices for water splitting in which the electrons and holes generated by a single semiconductor are used to carry out the hydrogen and oxygen evolution reactions. Unfortunately, studies show that the efficiency of single-photon PEC devices at the best cannot exceed $\sim 11 \%$, and if losses are taken into account the efficiency is even lower [10-15].

In order to circumvent the issue of relatively low efficiency of single-photon PEC water splitting, the tandem PEC architecture is being explored as a potential alternative. The tandem PEC device has two semiconductors of different band gaps working in juxtaposition. The lower end of the

\footnotetext{
*mohpa@fysik.dtu.dk

${ }^{\dagger} \mathrm{kwj} @$ fysik.dtu.dk
}

solar spectrum is absorbed by the smaller band gap (SBG) semiconductor with band gap of $\sim 1.1 \mathrm{eV}$, whereas the more energetic photons are absorbed by the larger band gap (LBG) semiconductor with a band gap of $\sim 1.8 \mathrm{eV}$ [16]. This way the two semiconductors working in series enhance the voltage and increase the overall efficiency for the water splitting process. It has been estimated that an ideal tandem PEC device may have efficiency as high as $\sim 29 \%$, and if the losses are taken into account, realistic estimates of the efficiency are close to $\sim 21 \%$ which is much higher than the efficiency of the single-photon PEC devices $[11,12,17,18]$. Therefore, in order to reach higher efficiency for the water splitting reaction it is essential to resort to tandem devices instead of the singlephoton architecture.

In the past three decades, attempts have been made to realize efficient tandem devices. Some of the semiconductors which have been explored are $\mathrm{WO}_{3}$, GaInP, $\mathrm{Cu}_{2} \mathrm{O}, \mathrm{BiVO}_{4}$, and $\mathrm{Fe}_{2} \mathrm{O}_{3}$ [5,19-22]. However, these materials face some challenges for their successful deployment, to name a few; corrosion, nonoptimal band gap, and poor charge transport. Therefore, it is essential that new materials are investigated to probe their suitability for tandem water splitting. Unfortunately, the experimental synthesis and characterization of many new materials is a challenging task and this is where the computational investigation of the materials becomes important. Computational screening with a set of descriptors provides an economically viable and faster way of scanning a large set of materials for their suitability in a particular application which in the present case is the PEC tandem devices.

In this study we focus on the chalcogenides similar to $\mathrm{Cu}_{2} \mathrm{ZnSnS}_{4}$ (CZTS). A large amount of work has been done on CZTS and its few variants which are derived by modifying the crystal structure or by elemental substitution(s) [3,4,23-32]. However, most of the works were focused on exploring materials for single-junction PV devices and not for 


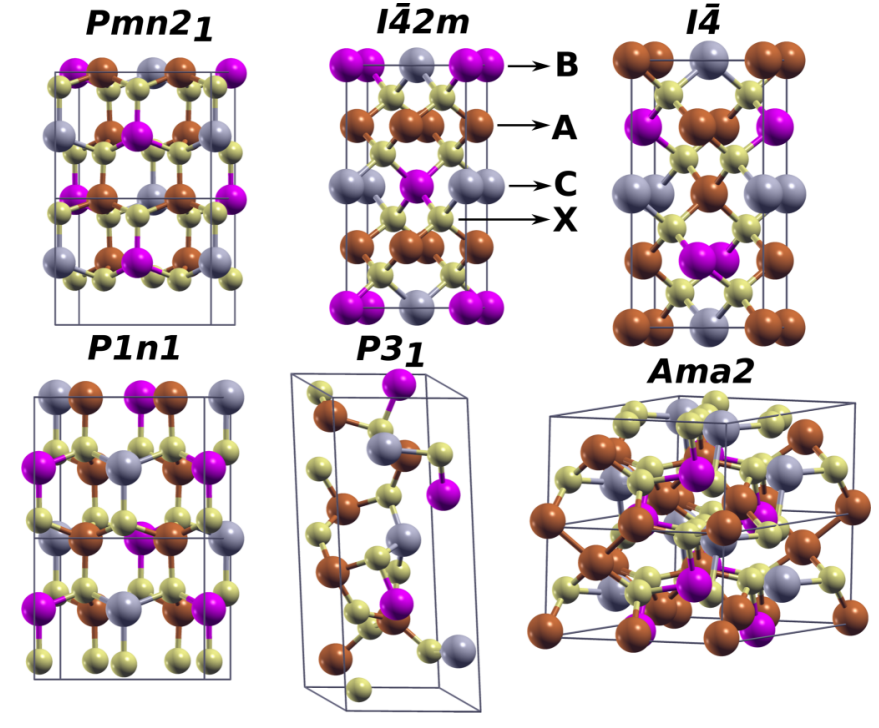

FIG. 1. Atomic structure of the different prototypes. The species $A$ is a cation with +1 oxidation state and can be either $\mathrm{Cu}$ or $\mathrm{Ag}$; the cation $B$ having $+2(+1)$ oxidation state belongs to the group Be, $\mathrm{Mg}, \mathrm{Ca}, \mathrm{Sr}, \mathrm{Ba}, \mathrm{Zn}$, and $\mathrm{Cd}(\mathrm{Li}, \mathrm{Na}, \mathrm{Rb}, \mathrm{Cs}) ; C$ is a cation with +4 $(+5)$ oxidation state chosen from the group $\mathrm{Si}, \mathrm{Ge}, \mathrm{Sn}, \mathrm{Ti}, \mathrm{Zr}$, and $\mathrm{Hf}$ $(\mathrm{V}, \mathrm{Nb}, \mathrm{Ta}) ; X$ is a chalcogen anion with the oxidation state -2 and is either $\mathrm{S}$ or Se. The space-group numbers corresponding to $P m n 2_{1}$, $I \overline{4} 2 m, I \overline{4}, P 1 n 1, P 3_{1}$, and $A m a 2$ are 31, 121, 82, 7, 144, and 40.

tandem PEC applications. Recently, Mitzi's group synthesized and characterized $\mathrm{Cu}_{2} \mathrm{BaSnS}_{4}$, which in addition to having a different crystal structure than CZTS also has different optoelectronic properties, for example, a band gap of $\sim 2 \mathrm{eV}$ which is higher than the band gap of CZTS $(\sim 1.3 \mathrm{eV})[33,34]$. Also, in an attempt to control the defect properties, Gershon et al. explored the possibility of substitution of copper and sulfur with silver and selenium, respectively [35,36]. As a result of copper substitution with silver, the amount of band tailing decreases indicating less structural disorder. These experiments indicate that there is a great potential in engineering the properties of CZTS-like materials and theoretical attempts are already being made to expand the materials space beyond CZTS for optoelectronic applications $[37,38]$.

In this work, we select six different crystal structures which are predominant in the Inorganic Crystal Structure Database (ICSD) for $A_{2} B C X_{4}$-type chalcogenides [39]. They belong to the space groups (space-group number) $P 3_{1}$ (144), $P m n 2_{1}$ (31), $I \overline{4} 2 m$ (121), $P 1 n 1$ (7), $I \overline{4}$ (82), and Ama2 (40). The elements constituting the compounds are selected in a way such that the weighted sum of the oxidation states adds up to zero. The stability of the compounds is assessed via the convex-hull approach in which the possibility of dissociation of the compound to competing phases is considered [40]. Additionally, the energy differences between the different prototypes, along with the error bars, are calculated with the Bayesian error estimation functional. In many cases, the energy differences turn out be very small, therefore, implying that more than one phase could be observed in the synthesis of these compounds. The ability of the materials to absorb photons in the visible spectrum is estimated by the size of the band gap. For the calculation of the band gap we use the GLLB-SC functional which in previous works has been shown to predict band gaps which are close to the band gaps calculated with higher-level methods like many-body perturbation theory (GW) or hybrid functionals. Finally, under the assumption that the transport of the charge carriers takes place through the band conduction mechanism, we use the effective masses of the charge carriers as descriptors of the mobilities. All the above criteria, i.e., thermodynamic stability under normal conditions, band gap in the visible spectrum, and low effective masses, when applied together result in a short list of compounds which may be suitable for tandem PEC devices.

In addition to the criteria mentioned above, few other restrictions can be imposed. To name a few: (1) the position of the valence band maximum (VBM) and the conduction band minimum (CBM) with respect to the water redox level; (2) lattice mismatch at the interface between different semiconductors; (3) corrosion of the cell under aqueous condition. However, we do not take these criteria into account for the reasons mentioned below.

Regarding the positions of the VBM and CBM with respect to the water redox level, recent works have shown that the band edges can be tuned to a large extent to match with the water redox levels by using $p$ - $n$ homojunctions or surface modification [16,41]. Therefore, given the possibility of tuning the band edge positions removing materials with "wrong" VBM/CBM positions is too restrictive. Also, calculating the absolute VBM/CBM positions with DFT calculations has its own challenges. For example, the VBM/CBM positions will depend on the surface termination, the presence of solvent, etc. However, Butler and Ginley proposed an empirical way to calculate the VBM/CBM of the semiconductors based on the Mulliken electronegativity of the constituent elements [42]. The band edges calculated in this way are independent of the surface termination or the surrounding environment. Therefore, the calculated values must be used with caution. Empirically, it is calculated as

$$
E_{\mathrm{VB}, \mathrm{CB}}=\left(\chi_{A}^{2} \chi_{B} \chi_{C} \chi_{X}^{4}\right)^{1 / 8} \pm E_{\mathrm{gap}} / 2+E_{0},
$$

where $E_{\mathrm{VB}, \mathrm{CB}}$ denote the band edge positions, and $\chi$ 's denote the electronegativity of the elements $A, B, C$, and $X, E_{\text {gap }}$ represents the band gap, and $E_{0}=-4.5 \mathrm{~V}$ is the normal hydrogen electrode (NHE) with respect to the vacuum. An analysis using the above formula is carried out on the final list of LBG candidates at the end of the Sec. III.

Second, the morphology of the film grown for the device is polycrystalline, therefore, there is no direct way to match interfaces between the large-band-gap and the small-band-gap semiconductors. Also, the low-band-gap material could be many different ones. Therefore, studying a single interface is itself quite challenging and may not prove useful in the end. On the other hand, given the tetrahedral nature of the semiconductors explored in this work, it is very likely that the lattice mismatch between the LBG semiconductor and a typical SBG semiconductor silicon will be quite small. However, if the epitaxial single-crystal growth is adopted to make a tandem architecture then it would be important to consider lattice mismatch whereas it will not matter much in colloidal synthesis or vapor deposition due to the polycrystalline nature 


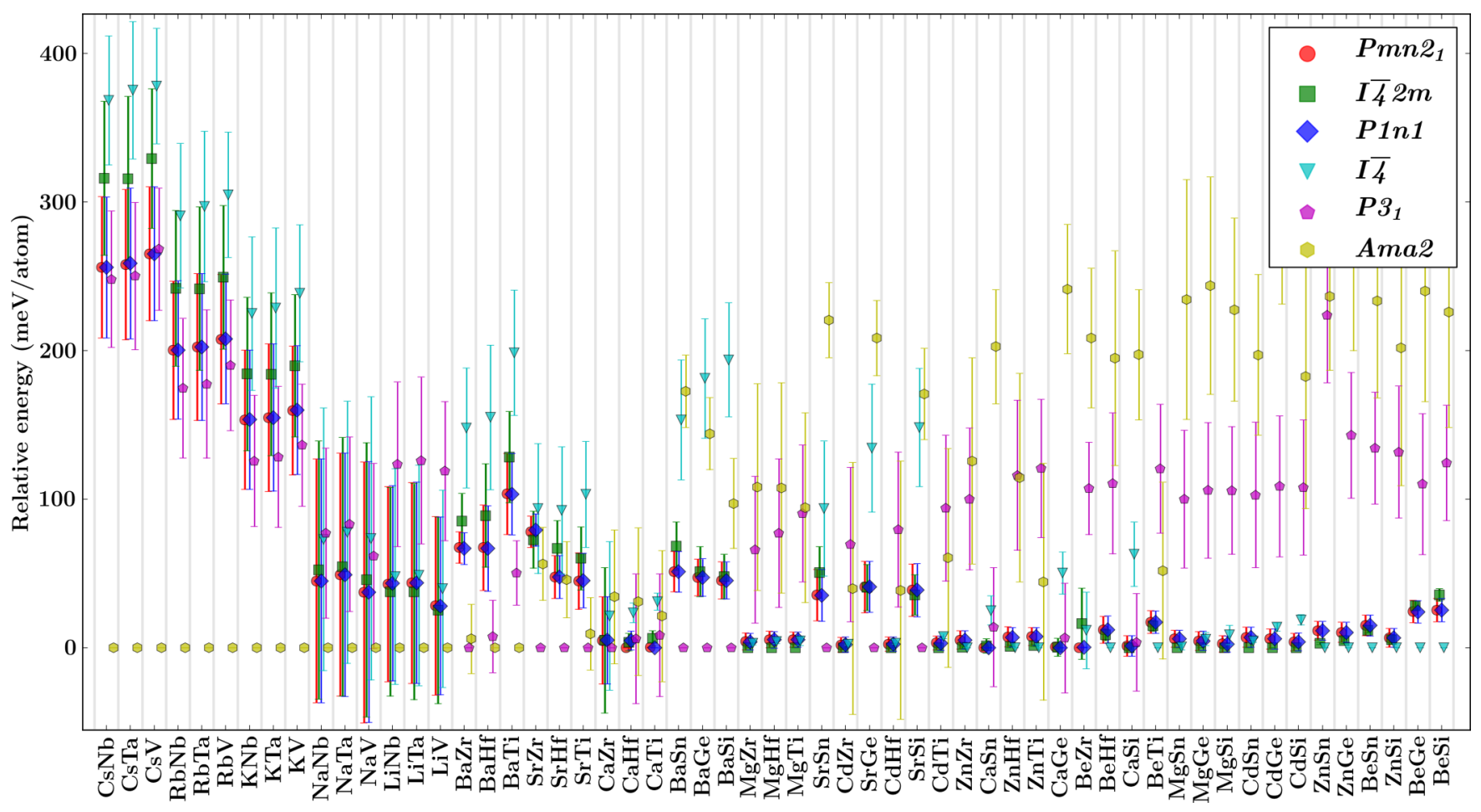

FIG. 2. The relative energies of all the copper quaternary sulfides with the general formula $\mathrm{Cu}_{2} B C \mathrm{~S}_{4}$. For brevity, only the $B$ and $C$ are shown in the name of the compounds. The energies and the error bars are plotted with respect to the phase having the lowest energy. In all the cases, the $P m n 2_{1}$ and $P 1 n 1$ phases are very close in energy and in many cases close to the $I \overline{4} 2 m$ and $I \overline{4}$ phases as well. However, Ama 2 and $P 3_{1}$ phases are different in energy from the above group in a large number of cases.

of the growth. Therefore, it is justified to exclude these criteria in our study.

Lastly, for photocorrosion to take place [43], a generated electron or hole must carry out a reaction between the semiconductor and water instead of evolving hydrogen or oxygen by splitting water. However, if the semiconductor is not in a direct contact with water, then the photocorrosion is prevented. In modern cell designs the protection layers (PL) protect the dissolution of the semiconductor(s) by preventing any direct contact of the semiconductor with water $[16,44]$. Also, there is no easy way to define a descriptor for corrosion. Pourbaix diagram which is usually used in corrosion studies takes only thermodynamics into account with no kinetics information at all. Therefore, the corrosion processes which are kinetically assisted/hampered cannot be studied with a thermodynamic model. Therefore, by throwing away the materials based on the criteria of photocorrosion may end up discarding materials which are otherwise very promising, and the use of PL can prevent them from corroding.

\section{COMPUTATIONAL DETAILS}

The electronic structure calculations are carried out using the open-source code GPAW using ASE as a simulation environment $[45,46]$. For a reliable estimate of the lattice constants, the PBEsol functional is used [47]. A plane-wave basis set with an energy cutoff of $800 \mathrm{eV}$ is used to expand the wave functions. For the structure optimization, a Monkhorst-Pack $k$-point mesh of $7 \times 7 \times 4$ for $P 3_{1}, I \overline{4} 2 m$, and $I \overline{4}$ space groups, $7 \times 7 \times 7$ for $P m n 2_{1}$ and $P 1 n 1$ space groups, and $8 \times 4 \times 8$ for Ama2 space group is used [48]. Finer $k$-point meshes are used for the calculation of effective masses and the effective masses are converged within $0.05 \mathrm{~m}_{e}$. The smearing of the occupation numbers is done using a Fermi-Dirac distribution with a width of $0.01 \mathrm{eV}$. All the structures are relaxed until the forces converge to $0.01 \mathrm{eV} / \AA$ or less. The energies are converged within $10^{-4} \mathrm{eV}$ and the unit cells have been relaxed until the pressure reaches $0.01 \mathrm{eV} / \AA^{3}$ or less.

The total energies along with the error bars are calculated using the recently developed meta-GGA functional, meta Bayesian error estimation functional (mBEEF) [49]. The mBEEF functional has shown to predict heats of formation of solids which are very close to the experiments [50].

\section{RESULTS AND DISCUSSION}

Figure 1 shows the atomic structure of the different prototypes explored in this work. The chemical formula of the compounds is denoted as $A_{2} B C X_{4}$. The species $A$ is a cation with +1 oxidation state and is either $\mathrm{Cu}$ or $\mathrm{Ag}$; the cation $B$ having $+2(+1)$ oxidation state belongs to the group $\mathrm{Be}, \mathrm{Mg}$, $\mathrm{Ca}, \mathrm{Sr}, \mathrm{Ba}, \mathrm{Zn}$, and $\mathrm{Cd}(\mathrm{Li}, \mathrm{Na}, \mathrm{Rb}, \mathrm{Cs}) ; C$ is a cation with +4 $(+5)$ oxidation state chosen from the group $\mathrm{Si}, \mathrm{Ge}, \mathrm{Sn}, \mathrm{Ti}, \mathrm{Zr}$, and $\mathrm{Hf}(\mathrm{V}, \mathrm{Nb}, \mathrm{Ta}) ; X$ is a chalcogen anion with the oxidation state -2 and is either $S$ or Se. Heuristically, the weighted sum of the oxidation state (with sign) has to add up to zero for a material to be a semiconductor. However, by no means is this a sufficient condition for a material to be a semiconductor but this rule can be used as a guideline to narrow down the 

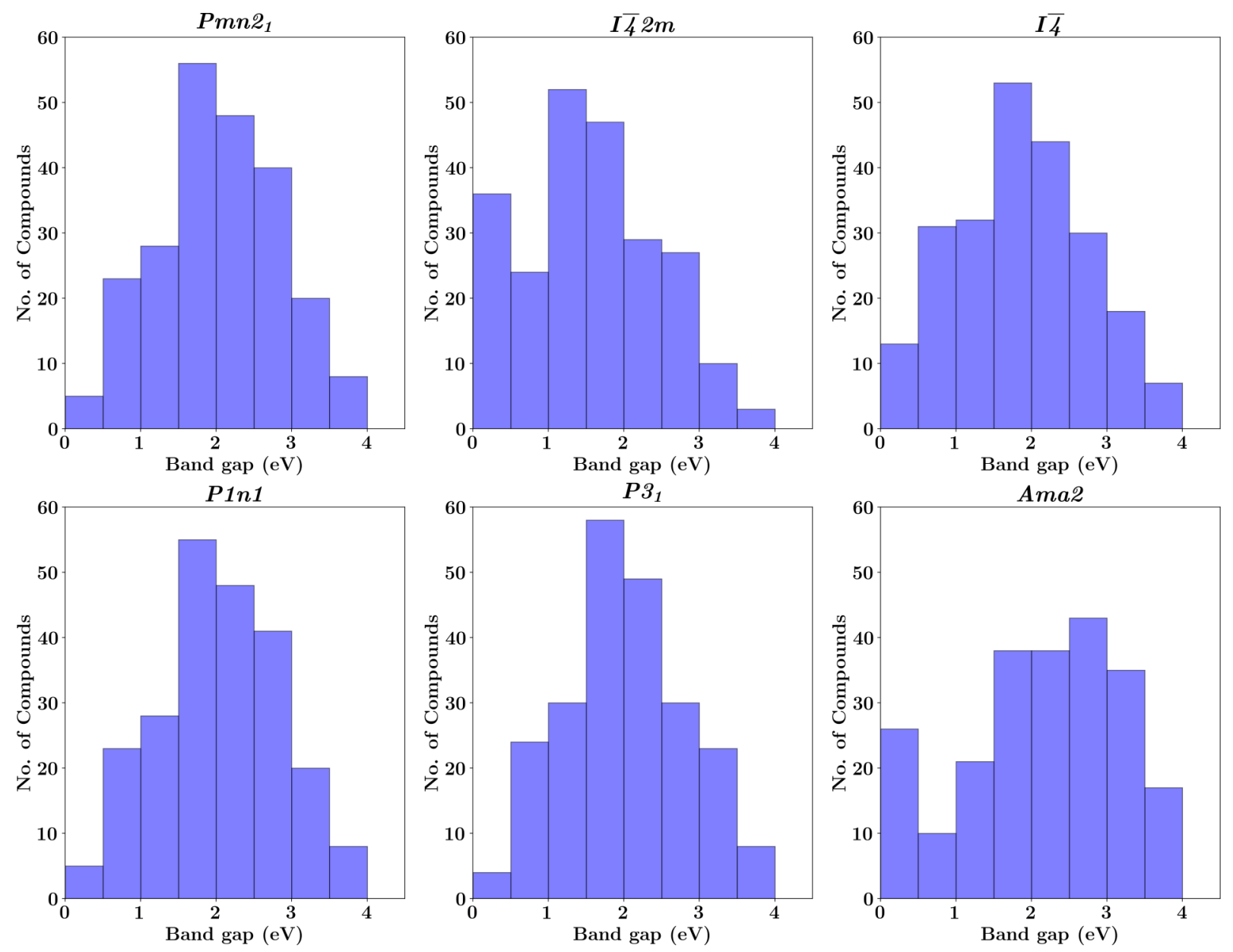

FIG. 3. Histogram of the band gap of all the compounds (1368 total including the multiplicity due to different phases) in 6 different phases. The distribution has significant number of compounds in the band-gap range of $1.5-2.5 \mathrm{eV}$ which is a relevant range for the tandem PEC devices.

number of materials to be explored. The selection of materials mentioned above clearly indicates that the weighted sum of the oxidation states is zero in all the cases. Additionally, we have avoided the elements which may exist in multiple oxidation states or have the potential to be magnetic. This way, the total number of compounds in each prototype is 228 $\left(228 \times 6=1368\right.$ total). Figure 1 also shows that the $P m n 2_{1}$, $I \overline{4} 2 m, P 1 n 1, I \overline{4}, P 3_{1}$ are tetrahedrally bonded with similar or dissimilar elements at the vertices of the tetrahedron. On the other hand, Ama2 has significant differences from the above group in terms of the atomic structure.

Figure 2 shows the energies of all the copper quaternary sulfides with the general formula $\mathrm{Cu}_{2} B C \mathrm{~S}_{4}$, i.e., only the $B$ and $C$ are varied in the composition in $A_{2} B C X_{4}$ and $A$ is fixed to copper and $X$ to sulfur. The energies and the error bars of each compound are plotted with respect to the phase with the lowest energy. The plot clearly shows that the Ama2 phase is the most stable one in the compounds where the oxidation states of $B$ and $C$ are +1 and +5 , respectively. Also, the $P 3_{1}$ phase is energetically favored in numerous cases where the $B$ atom is either $\mathrm{Sr}$ or $\mathrm{Ba}$ which is also seen experimentally, for example, in the case of $\mathrm{Cu}_{2} \mathrm{BaSnS}_{4}$ [33,51]. On the other hand, the compounds containing $\mathrm{Be}, \mathrm{Mg}, \mathrm{Ca}, \mathrm{Zn}$, or $\mathrm{Cd}$ as $B$ have $P m n 2_{1}, I \overline{4} 2 m, I \overline{4}, P 1 n 1$ phases very close in energy and they are usually more stable than the $A m a 2$ and $P 3_{1}$ phases. This general trend is also observed in selenium or silver-containing compounds (see [52]). One feature of the plot which needs further explanation is the size of the error bars of the energies. In general, the error bar on an energy difference between two phases will be relatively small when the two phases are similar because this difference can be reliably calculated with DFT. In contrast, the error bar will be larger if the phases are dissimilar [50]. In our case, the phases $A m a 2$ and $P 3_{1}$ are rather different from the other phases so error bars involving these phases tend to be larger. This also means that if one of these two phases is the most stable one, the error bars on the other phases in Fig. 2 are large because they are calculated relative to the most stable phase. In the situation where several phases are very close in energy, so the differences in energies are within the error bar, the predicted ground state may not be the true ground state and other phase(s) of the compound may be observed experimentally.

As mentioned before, the tandem PEC device requires that the large-band-gap semiconductor should have a band gap of $\sim 2 \mathrm{eV}$. In order to account for the overestimation/underestimation of the band gap with the GLLB-SC functional, we take a window of $\pm 0.5 \mathrm{eV}$, i.e., the range of 

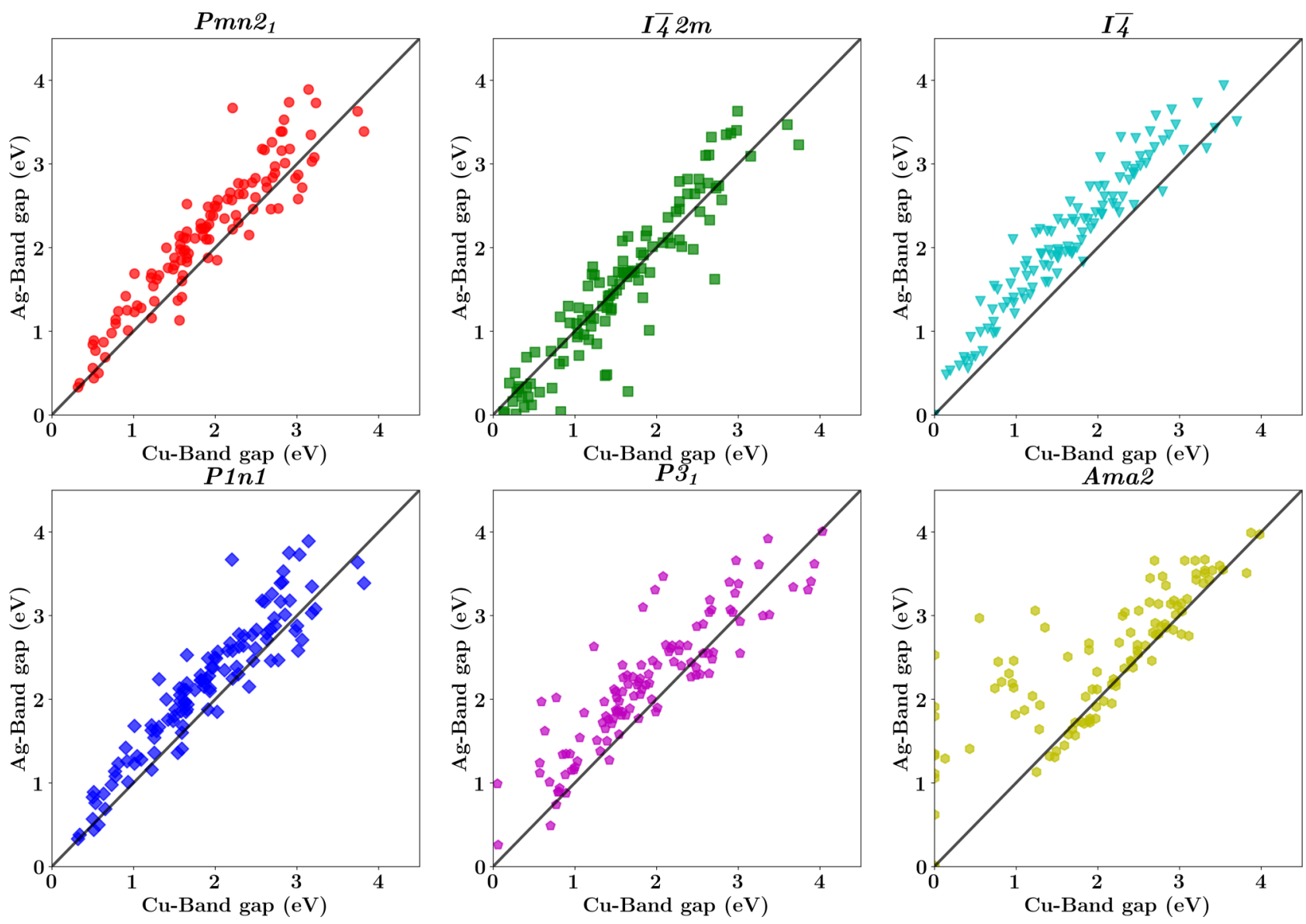

FIG. 4. Band gap of silver-containing compounds versus the copper-containing ones in six different phases. On an average the silver-based compounds have higher band gaps than the copper ones except in the $I \overline{4} 2 \mathrm{~m}$ prototype in which the copper and silver compounds have similar average band gap.

1.5-2.5 eV as relevant for tandem PEC applications. Figure 3 shows the histograms of the band gaps of all the compounds in the six different phases. The distribution has a significant number of compounds with the band gap in the range $1.5-2.5 \mathrm{eV}$. The band gaps of all the phases are peaked around the desired range except for the Ama2 phase. Therefore, it is very likely that some interesting candidates can be found for this class of materials.

Recently, Gershon et al. explored $\mathrm{Ag}_{x} \mathrm{Cu}_{2-x} \mathrm{ZnSnSe}_{4}$ mainly to investigate the effect of copper replacement with silver $[35,36]$. They suggest that one of the primary defects, which is the $\mathrm{Cu}-\mathrm{Zn}$ antisite defect, deteriorates the performance of CZTS and can be suppressed by introducing silver, which is larger in size than copper. The larger size of the silver atoms will increase the energy to form the Ag- $\mathrm{Zn}$ antisite defect as compared to the $\mathrm{Cu}-\mathrm{Zn}$ antisite defect because of the very dissimilar sizes of the silver and zinc atoms. Therefore, suppression of the antisite defects in silver-based devices may lead to improved optoelectronic properties. Probably, due to this reason the newly explored silver devices give a reasonable efficiency of $\sim 5 \%$. Figure 4 shows the band gap of silver-containing compounds versus the copper-containing ones in the six different phases. On an average, the silverbased compounds tend to have higher band gaps than the copper-containing ones. The $I \overline{4} 2 m$ prototype is an exception where the average behavior seems to be the same. The larger band gap of AgZTSe than CZTSe has also been observed experimentally $[35,53]$. This provides an opportunity to selectively tune the band gap and possibly control the defect properties in a predictive way as mentioned above.

As discussed above, the substitution of copper with silver, or sulfur with selenium, has noticeable effects on the properties of the class of materials explored here. However, the substitution is not limited to copper or sulfur and the substitutions of $B$ and $C$ in $A_{2} B C X_{4}$ may also lead to new potential materials for the tandem PEC. For example, the substitution of zinc with barium gives $\mathrm{Cu}_{2} \mathrm{BaSnS}_{4}$ which has a different crystal structure and promising properties, which have been explored in the past few years for the PEC applications [33,34,51]. In order to see the possible effect of the other substitutions, the variation in the band gap of the compounds is plotted in Fig. 5 for the $I \overline{4}$ phase when an element is replaced with another one with the same oxidation state. The average difference and the mean absolute deviation are shown with the diamond symbol along with the error bars. Five different groups in the plot correspond to the different oxidation states except the group in which the copper and the sulfur groups are put together for convenience. The dark vertical lines divide the groups into subgroups corresponding to the elements being substituted. The plot shows several useful trends that can be exploited for band-gap tuning. As mentioned before, the substitution of copper and selenium with silver and sulfur, respectively, 

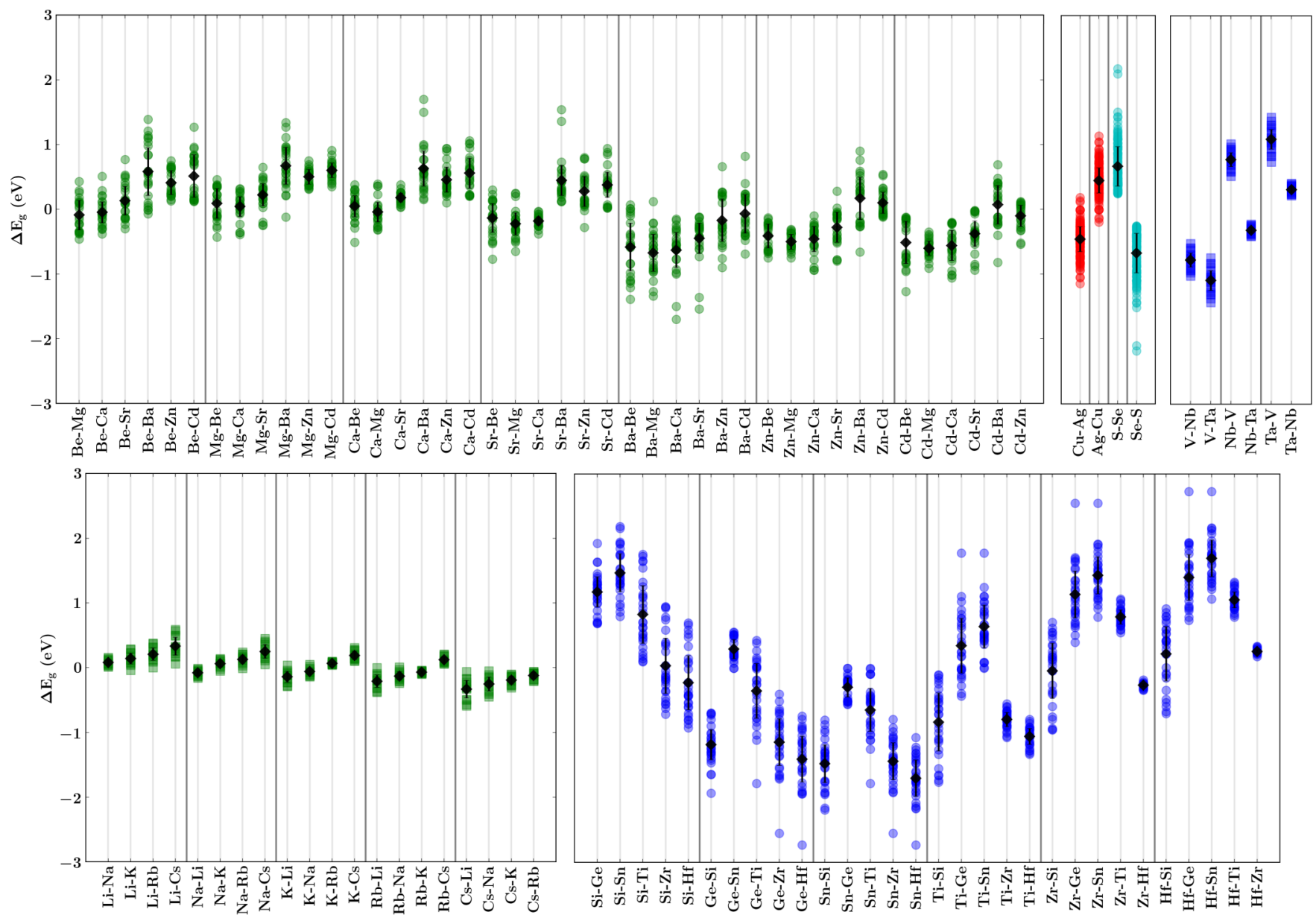

FIG. 5. The variation in the band gap when an element is replaced with another one with the same oxidation state in $I \overline{4}$ phase. For example, $\mathrm{Zn}$ is replaced with $\mathrm{Cd}$ or $\mathrm{S}$ replaced with Se, etc. The black diamond symbols show the average difference and the error bars show the mean absolute deviation. The plot is divided into five groups, one for each kind of the oxidation state in $A_{2} B C X_{4}(\mathrm{Cu}, \mathrm{S}$ groups are combined), and the subgroups (dark vertical lines) in the groups correspond to the first element (first element in the axis label) which is substituted by the second one (second element in the axis label).

leads to an average increase in the band gap. In the group with +2 oxidation state, the average deviation is quite small for $\mathrm{Be}$ substitution with $\mathrm{Mg}, \mathrm{Ca}$, and $\mathrm{Sr}$, however, $\mathrm{Ba}, \mathrm{Zn}$, and $\mathrm{Cd}$ substitution tends to increase the band gap. Similarly, for $\mathrm{Mg}$, $\mathrm{Ca}$, and $\mathrm{Sr}$, larger average positive deviation is seen with $\mathrm{Ba}$, $\mathrm{Zn}$, and $\mathrm{Cd}$ substitution implying that $\mathrm{Ba}, \mathrm{Zn}$, and $\mathrm{Cd}$ have the tendency to increase the band gap. The compounds in which $B$ and $C$ correspond to +1 and +5 oxidation states, respectively, show a very clear trend. The average band gap decreases when going down the periodic table, i.e., from $\mathrm{V}$ to Ta. On the other hand, the average deviation is quite small for the alkali substitutions which may be due to the fact that they merely act as electron donors to the lattice, thus leading to nominal changes after the substitution. The above analyses may differ slightly for the different phases. Similar plots for the other phases are provided in [52].

The discussion above was mainly focused on the trends in stability and the band gap to shed light on how to tune these properties. Now, we turn to the issue of finding candidates for the tandem PEC device from the data presented above. As discussed before, some of the decisive factors in the selection of materials for the tandem device are thermodynamic stability, band gap appropriate for visible light absorption, and low electron and hole effective masses for high mobility under the assumption of the band conduction mechanism. The criteria we impose for a material to qualify as a potential candidate are as follows:

(1) The most stable phase of the material has to be stable against dissociation into competing elemental and binary compounds. Additionally, all the phases whose energy error bar straddles the most stable phase are considered. Together with the most stable phase we call these phases "competing polymorphs" [40].

(2) The band gap of all the competing polymorphs should be in the appropriate range for the tandem PEC devices, i.e., $1.5-2.5 \mathrm{eV}$.

(3) The absolute values of the charge carrier effective masses (in the units of electron mass $m_{e}$ ) of all the competing polymorphs should be below 0.5 in at least two directions.

The thermodynamic stability mentioned in point 1 is evaluated by constructing a convex hull using the standard states of the elements, and of the binary sulfides and selenides. The ternary compounds have not been considered because of the very large size of the ternary materials space. For 
TABLE Ia. List of materials with $\mathrm{Cu}_{2} B C \mathrm{~S}_{4}$ stoichiometry. The listed materials are below the convex hull, and have the band gap in the desired range of 1.5-2.5 eV for tandem PEC devices. The materials which fulfill the criterion that at least two of the effective masses for both electrons and holes are smaller than 0.5 are indicated in bold. The electron and hole effective masses are denoted as $m_{e}^{*}$ and $m_{h}^{*}$, respectively. $E_{g}$ and $\Delta H_{\text {hull }}$ represent the band gap in $\mathrm{eV}$ and the energy with respect to the convex hull in $\mathrm{eV} /$ atom. The b, c, and d parts of the table are for materials with stoichiometry $\mathrm{Cu}_{2} \mathrm{BCSe}_{4}, \mathrm{Ag}_{2} \mathrm{BCS}_{4}$, and $\mathrm{Ag}_{2} \mathrm{BCSe}_{4}$, respectively. Different compounds are separated with alternating gray and white colors.

\begin{tabular}{|c|c|c|c|c|c|}
\hline Formula & Phase & $E_{g}\left(\right.$ type, $\left.E_{g}^{\mathrm{D}}-E_{g}^{\mathrm{I}}\right)$ & $m_{h}^{*}$ & $m_{e}^{*}$ & $\Delta H_{\text {hull }}$ \\
\hline $\mathrm{Cu}_{2} \mathrm{CsVS}_{4}$ & $A m a 2$ & $1.97(\mathrm{I}, 0.08)$ & $\mathrm{H}, 0.79, \mathrm{H}$ & $\mathrm{H}, \mathrm{H}, 1.75$ & $-0.53 \pm 0.11$ \\
\hline $\mathrm{Cu}_{2} \mathrm{RbVS}_{4}$ & Ama2 & $1.89(\mathrm{I}, 0.04)$ & $2.11,2.64,1.04$ & H, H, 1.99 & $-0.52 \pm 0.11$ \\
\hline $\mathrm{Cu}_{2} \mathrm{KVS}_{4}$ & $A m a 2$ & $1.83(\mathrm{I}, 0.01)$ & $1.62,1.25,2.24$ & H, H, 1.76 & $-0.50 \pm 0.11$ \\
\hline $\mathrm{Cu}_{2} \mathrm{BaSnS}_{4}$ & $P 3_{1}$ & $1.53(\mathrm{D},--)$ & $0.37,0.36,1.36$ & $0.17,0.17,0.23$ & $-0.14 \pm 0.08$ \\
\hline $\mathrm{Cu}_{2} \mathrm{BaGeS}_{4}$ & $P 3_{1}$ & $2.30(\mathrm{I}, 0.01)$ & $0.42,0.42,1.49$ & $0.21,0.21,0.26$ & $-0.16 \pm 0.09$ \\
\hline $\mathrm{Cu}_{2} \mathrm{MgTiS}_{4}$ & $I \overline{4} 2 m$ & $1.87(\mathrm{D},--)$ & $1.41,1.31,1.31$ & $1.45,1.45,0.44$ & $-0.14 \pm 0.14$ \\
\hline $\mathrm{Cu}_{2} \mathrm{SrSnS}_{4}$ & $P 3_{1}$ & $1.58(\mathrm{D},--)$ & $0.35,0.33,1.32$ & $0.17,0.17,0.24$ & $-0.11 \pm 0.08$ \\
\hline $\mathrm{Cu}_{2} \mathrm{SrGeS}_{4}$ & $P 3_{1}$ & $2.42(\mathrm{D},--)$ & $0.40,0.39,1.48$ & $0.21,0.21,0.28$ & $-0.13 \pm 0.08$ \\
\hline $\mathrm{Cu}_{2} \mathrm{CdTiS}_{4}$ & $I \overline{4} 2 m$ & $1.73(\mathrm{I}, 0.02)$ & $0.58, \mathrm{H}, \mathrm{H}$ & $0.89,0.89,2.49$ & $-0.14 \pm 0.13$ \\
\hline $\mathrm{Cu}_{2} \mathrm{CdTiS}_{4}$ & $P 1 n 1$ & 1.92 (I, 0.07) & $0.98,1.31,0.68$ & $\mathrm{H}, 1.27, \mathrm{H}$ & $-0.14 \pm 0.13$ \\
\hline $\mathrm{Cu}_{2} \mathrm{CdTiS}_{4}$ & $P m n 2_{1}$ & $1.92(\mathrm{I}, 0.07)$ & $0.98,0.68,1.30$ & H, H, 1.28 & $-0.14 \pm 0.13$ \\
\hline $\mathrm{Cu}_{2} \mathrm{CdTiS}_{4}$ & $A m a 2$ & $1.99(\mathrm{I}, 0.01)$ & $\mathrm{H}, 2.81,0.34$ & $2.37,1.23,0.76$ & $-0.08 \pm 0.07$ \\
\hline $\mathrm{Cu}_{2} \mathrm{CaSnS}_{4}$ & $P 1 n 1$ & $1.91(\mathrm{D},--)$ & $\mathrm{H}, 0.26,2.80$ & $0.29,0.27,0.23$ & $-0.06 \pm 0.09$ \\
\hline $\mathrm{Cu}_{2} \mathrm{CaSnS}_{4}$ & $P m n 2_{1}$ & $1.91(\mathrm{D},--)$ & $\mathrm{H}, 0.25,2.79$ & $0.29,0.28,0.23$ & $-0.06 \pm 0.09$ \\
\hline $\mathrm{Cu}_{2} \mathrm{CaSnS}_{4}$ & $I \overline{4} 2 m$ & $2.14(\mathrm{D},--)$ & $1.44,0.84,0.56$ & $0.31,0.31,0.23$ & $-0.06 \pm 0.10$ \\
\hline $\mathrm{Cu}_{2} \mathrm{CaSnS}_{4}$ & $P 3_{1}$ & $1.64(\mathrm{D},--)$ & $0.36,45,1.62$ & $0.21,0.21,0.26$ & $-0.04 \pm 0.07$ \\
\hline $\mathrm{Cu}_{2} \mathrm{ZnTiS}_{4}$ & $I \overline{4}$ & $1.68(\mathrm{I}, 0.29)$ & $0.59,1.22,1.08$ & $0.46,1.26,1.26$ & $-0.14 \pm 0.13$ \\
\hline $\mathrm{Cu}_{2} \mathrm{ZnTiS}_{4}$ & Ama2 & $1.90(\mathrm{I}, 0.05)$ & $0.85, \mathrm{H}, \mathrm{H}$ & $0.81, \mathrm{H}, 2.10$ & $-0.09 \pm 0.08$ \\
\hline $\mathrm{Cu}_{2} \mathrm{BeTiS}_{4}$ & $I \overline{4}$ & $1.81(\mathrm{I}, 0.36)$ & $0.78,0.78,1.47$ & $1.58,1.58,0.71$ & $-0.36 \pm 0.15$ \\
\hline $\mathrm{Cu}_{2} \mathrm{BeTiS}_{4}$ & Ama2 & $2.07(\mathrm{D},--)$ & $0.77, \mathrm{H}, \mathrm{H}$ & $0.68, \mathrm{H}, \mathrm{H}$ & $-0.31 \pm 0.11$ \\
\hline $\mathrm{Cu}_{2} \mathrm{MgSnS}_{4}$ & $I \overline{4} 2 m$ & $1.60(\mathrm{D},--)$ & $1.26,1.26,0.29$ & $0.30,0.30,0.18$ & $-0.12 \pm 0.12$ \\
\hline $\mathrm{Cu}_{2} \mathrm{MgSnS}_{4}$ & $I \overline{4}$ & $1.51(\mathrm{D},--)$ & $0.98,0.98,0.45$ & $0.21,0.21,0.20$ & $-0.12 \pm 0.12$ \\
\hline $\mathrm{Cu}_{2} \mathrm{MgGeS}_{4}$ & $I \overline{4} 2 m$ & $2.17(\mathrm{D},--)$ & $0.78,0.78,0.80$ & $0.23,0.34,0.34$ & $-0.13 \pm 0.12$ \\
\hline $\mathrm{Cu}_{2} \mathrm{MgGeS}_{4}$ & $P m n 2_{1}$ & $2.28(\mathrm{D},--)$ & $0.40, \mathrm{H}, 1.58$ & $0.35,0.23,0.30$ & $-0.13 \pm 0.11$ \\
\hline $\mathrm{Cu}_{2} \mathrm{MgGeS}_{4}$ & $P 1 n 1$ & $2.28(\mathrm{D},--)$ & $0.40,1.59, \mathrm{H}$ & $0.35,0.30,0.23$ & $-0.12 \pm 0.11$ \\
\hline $\mathrm{Cu}_{2} \mathrm{ZnGeS}_{4}$ & $I \overline{4}$ & $1.69(\mathrm{D},--)$ & $0.19,0.80,0.80$ & $0.21,0.21,0.18$ & $-0.13 \pm 0.11$ \\
\hline $\mathrm{Cu}_{2} \mathrm{BeSnS}_{4}$ & $I \overline{4}$ & $1.80(\mathrm{D},--)$ & $\mathrm{H}, \mathrm{H}, 0.25$ & $0.26,0.25,0.25$ & $-0.35 \pm 0.12$ \\
\hline $\mathrm{Cu}_{2} \mathrm{BeGeS}_{4}$ & $I \overline{4}$ & $2.08(\mathrm{I}, 0.12)$ & $0.26,0.92,0.92$ & $0.81,0.59,0.48$ & $-0.36 \pm 0.13$ \\
\hline
\end{tabular}

a compound to be stable, its total energy has to be lower than the appropriately weighted average of the total energy of the competing compounds. Additionally, the possibility of existence of metastable phase(s) is taken into account by the calculated uncertainties in the energy. For example, both the Ama2 and $P 3_{1}$ phases of $\mathrm{Cu}_{2} \mathrm{BaHfS}_{4}$ (denoted as $\mathrm{BaHf}$ in Fig. 2) are considered potentially stable because the error bar of the $P 3_{1}$ phase straddles the Ama 2 phase. Consequentially, all the metastable phase(s) should fulfill the criteria of the band gap and effective masses. If the competing polymorph(s) have higher or lower band gap, the device may still work because of the dominant stable phase which has desired properties. However, in a situation where a competing polymorph is metallic, special care must be taken to avoid the formation of this phase because the presence of even a small amount of this phase may totally damage the device.

The criterion imposed on the effective masses requires an elaboration. In a general case, the effective mass is represented as a tensor with three eigenvectors and the corresponding eigenvalues. Each eigenvalue is the effective mass in the direction denoted by the corresponding eigenvector. If the synthesized material is a single crystal, then having just one low effective mass (for both electrons and holes) can suffice if the direction for the low effective mass coincides with direction where the charges have to be collected. However, since the synthesized materials are generally polycrystalline, one low effective mass will generally not be enough. In principle, all the three effective masses should be small for an efficient charge transport. On the other hand, it is very unlikely for a material to have all the three effective masses small. Therefore, we select materials which have at least two small effective masses (for both the charge carriers), i.e., less than or equal to $0.5 m_{e}^{*}$. The reason for imposing such strict criteria on the effective masses is twofold. First, as discussed before, low effective masses help in better charge transport. Second, it has been argued recently that the low effective mass may play a crucial role in the defect tolerance of the materials [54]. To elaborate, low effective mass will correspond to very delocalized electron/hole states leading to a significantly smaller overlap with localized defect states, which may be present due to different defects like vacancies, antisite defects, etc. The small overlap decreases the probability of recombination of the charge carriers at the defect site. This phenomenon prevents the losses due to recombination, which leads to an improved efficiency of the light absorption process. 
TABLE Ib. List of materials with $\mathrm{Cu}_{2} B C \mathrm{Se}_{4}$ stoichiometry.

\begin{tabular}{|c|c|c|c|c|c|}
\hline Formula & Phase & $E_{g}\left(\right.$ type, $\left.E_{g}^{\mathrm{D}}-E_{g}^{\mathrm{I}}\right)$ & $m_{h}^{*}$ & $m_{e}^{*}$ & $E_{\text {hull }}$ \\
\hline $\mathrm{Cu}_{2} \mathrm{CsVSe}_{4}$ & $A m a 2$ & $1.59(\mathrm{I}, 0.07)$ & H, H, H & $\mathrm{H}, 1.40, \mathrm{H}$ & $-0.42 \pm 0.02$ \\
\hline $\mathrm{Cu}_{2} \mathrm{RbVSe}_{4}$ & $A m a 2$ & $1.49(\mathrm{I}, 0.02)$ & $\mathrm{H}, 1.30,2.72$ & $\mathrm{H}, 2.93,1.54$ & $-0.41 \pm 0.02$ \\
\hline $\mathrm{Cu}_{2} \mathrm{KNbSe}_{4}$ & Ama2 & $2.40(\mathrm{I}, 0.04)$ & $1.62,1.25,2.24$ & H, H, 1.76 & $-0.18 \pm 0.07$ \\
\hline $\mathrm{Cu}_{2} \mathrm{LiNbSe}_{4}$ & Ama2 & $2.41(\mathrm{I}, 0.02)$ & $0.60,1.69,2.37$ & H, H, H & $-0.07 \pm 0.06$ \\
\hline $\mathrm{Cu}_{2} \mathrm{BaTiSe}_{4}$ & $A m a 2$ & $2.17(\mathrm{I}, 0.01)$ & $0.51,2.18,1.38$ & $1.59,1.78,1.82$ & $-0.47 \pm 0.04$ \\
\hline $\mathrm{Cu}_{2} \mathrm{SrTiSe}_{4}$ & Ama2 & $1.99(\mathrm{I}, 0.03)$ & $0.59,2.04,1.27$ & $1.16, \mathrm{H}, 2.05$ & $-0.98 \pm 0.06$ \\
\hline $\mathrm{Cu}_{2} \mathrm{CaTiSe}_{4}$ & $A m a 2$ & $2.26(\mathrm{D},--)$ & $0.82, \mathrm{H}, 1.74$ & $2.03,1.90,1.08$ & $-0.33 \pm 0.03$ \\
\hline $\mathrm{Cu}_{2} \mathrm{CaTiSe}_{4}$ & $I \overline{4} 2 m$ & $1.59(\mathrm{I}, 0.14)$ & $2.75,0.73,0.99$ & $1.60,1.60,0.38$ & $-0.32 \pm 0.05$ \\
\hline $\mathrm{Cu}_{2} \mathrm{CaTiSe}_{4}$ & $P 1 n 1$ & $2.11(\mathrm{I}, 0.04)$ & $0.72,1.38,1.68$ & $1.05,1.45, \mathrm{H}$ & $-0.31 \pm 0.04$ \\
\hline $\mathrm{Cu}_{2} \mathrm{CaTiSe}_{4}$ & $P m n 2_{1}$ & $2.11(\mathrm{I}, 0.04)$ & $0.72,1.38,1.66$ & $1.03,1.47, \mathrm{H}$ & $-0.31 \pm 0.04$ \\
\hline $\mathrm{Cu}_{2} \mathrm{CaTiSe}_{4}$ & $P 3_{1}$ & $1.94(\mathrm{D},--)$ & $0.75,1.20,1.93$ & $1.08,2.054, \mathrm{H}$ & $-0.31 \pm 0.02$ \\
\hline $\mathrm{Cu}_{2} \mathrm{CaTiSe}_{4}$ & $I \overline{4}$ & $1.60(\mathrm{I}, 0.45)$ & $0.77,2.07,1.65$ & $1.19,1.19, \mathrm{H}$ & $-0.30 \pm 0.05$ \\
\hline $\mathrm{Cu}_{2} \mathrm{BaSiSe}_{4}$ & $P 3_{1}$ & $2.42(\mathrm{D},--)$ & $\mathrm{H}, 0.23,0.22$ & $0.25,0.15,0.15$ & $-0.19 \pm 0.03$ \\
\hline $\mathrm{Cu}_{2} \mathrm{MgTiSe}_{4}$ & $I \overline{4} 2 m$ & $1.65(\mathrm{D},--)$ & $1.10,1.51,1.51$ & $1.44,1.44,0.39$ & $-0.73 \pm 0.08$ \\
\hline $\mathrm{Cu}_{2} \mathrm{MgTiSe}_{4}$ & $\operatorname{Pmn} 2_{1}$ & $1.85(\mathrm{I}, 0.08)$ & $0.90, \mathrm{H}, 1.12$ & $2.64,1.51, \mathrm{H}$ & $-0.73 \pm 0.07$ \\
\hline $\mathrm{Cu}_{2} \mathrm{MgTiSe}_{4}$ & $P 1 n 1$ & $1.86(\mathrm{I}, 0.08)$ & $0.91, \mathrm{H}, 1.18$ & $2.66,1.53, \mathrm{H}$ & $-0.73 \pm 0.07$ \\
\hline $\mathrm{Cu}_{2} \mathrm{CdZrSe}_{4}$ & $I \overline{4} 2 m$ & $2.08(\mathrm{D},--)$ & $1.41,1.41,2.10$ & $1.65,1.65, \mathrm{H}$ & $-0.10 \pm 0.06$ \\
\hline $\mathrm{Cu}_{2} \mathrm{CdZrSe}_{4}$ & $P 1 n 1$ & $2.29(\mathrm{I}, 0.01)$ & $\mathrm{H}, 0.87,1.07$ & $0.43,2.69, \mathrm{H}$ & $-0.09 \pm 0.06$ \\
\hline $\mathrm{Cu}_{2} \mathrm{CdZrSe}_{4}$ & $\operatorname{Pmn} 2_{1}$ & $2.29(\mathrm{I}, 0.01)$ & $\mathrm{H}, 0.89,1.04$ & $0.43, \mathrm{H}, 2.76$ & $-0.09 \pm 0.06$ \\
\hline $\mathrm{Cu}_{2} \mathrm{CdZrSe}_{4}$ & Ama 2 & $1.69(\mathrm{D},--)$ & $0.35, \mathrm{H}, \mathrm{H}$ & $0.27,0.69,0.48$ & $-0.09 \pm 0.05$ \\
\hline $\mathrm{Cu}_{2} \mathrm{ZnZrSe}_{4}$ & $I \overline{4}$ & $1.95(\mathrm{I}, 0.25)$ & H, H, 0.49 & $0.84,0.84,0.33$ & $-0.09 \pm 0.06$ \\
\hline $\mathrm{Cu}_{2} \mathrm{ZnZrSe}_{4}$ & $P 1 n 1$ & $2.15(\mathrm{D},--)$ & $1.82,1.14,0.94$ & $0.52,2.65,1.60$ & $-0.09 \pm 0.05$ \\
\hline $\mathrm{Cu}_{2} \mathrm{ZnZrSe}_{4}$ & $\operatorname{Pmn} 2_{1}$ & $2.15(\mathrm{D},--)$ & $1.65,0.96,1.15$ & $0.52,2.68,1.59$ & $-0.09 \pm 0.05$ \\
\hline $\mathrm{Cu}_{2} \mathrm{CaGeSe}_{4}$ & $I \overline{4} 2 m$ & $1.81(\mathrm{I}, 0.07)$ & $1.21,0.83,0.49$ & $0.30,0.30,0.15$ & $+0.02 \pm 0.04$ \\
\hline $\mathrm{Cu}_{2} \mathrm{CaGeSe}_{4}$ & $P 1 n 1$ & $1.64(\mathrm{D},--)$ & $\mathrm{H}, 0.15, \mathrm{H}$ & $0.37,0.15,0.22$ & $+0.02 \pm 0.04$ \\
\hline $\mathrm{Cu}_{2} \mathrm{CaGeSe}_{4}$ & $\operatorname{Pmn} 2_{1}$ & $1.65(\mathrm{D},--)$ & $\mathrm{H}, 0.14, \mathrm{H}$ & $0.38,0.22,0.15$ & $+0.02 \pm 0.04$ \\
\hline $\mathrm{Cu}_{2} \mathrm{CaGeSe}_{4}$ & $P 3_{1}$ & $1.51(\mathrm{D},--)$ & $0.18,0.17,2.11$ & $0.40,0.15,0.15$ & $+0.03 \pm 0.03$ \\
\hline $\mathrm{Cu}_{2} \mathrm{BeTiSe}_{4}$ & $I \overline{4}$ & $1.51(\mathrm{I}, 0.37)$ & $0.78,0.78,1.47$ & $1.45,1.45,0.64$ & $-0.56 \pm 0.09$ \\
\hline $\mathrm{Cu}_{2} \mathrm{BeTiSe}_{4}$ & Ama2 & $1.72(\mathrm{D},--)$ & $0.37, \mathrm{H}, \mathrm{H}$ & $0.82, \mathrm{H}, 2.81$ & $-0.54 \pm 0.05$ \\
\hline $\mathrm{Cu}_{2} \mathrm{MgSiSe}_{4}$ & $I \overline{4} 2 m$ & $2.31(\mathrm{D},--)$ & $0.65,0.65,0.59$ & $0.16,0.16,0.15$ & $-0.50 \pm 0.05$ \\
\hline $\mathrm{Cu}_{2} \mathrm{MgSiSe}_{4}$ & $P 1 n 1$ & $2.41(\mathrm{D},--)$ & $0.31,0.97,0.98$ & $0.18,0.17,0.15$ & $-0.50 \pm 0.05$ \\
\hline $\mathrm{Cu}_{2} \mathrm{MgSiSe}_{4}$ & $\operatorname{Pmn} 2_{1}$ & $2.41(\mathrm{D},--)$ & $0.31,0.97,0.98$ & $0.18,0.17,0.15$ & $-0.49 \pm 0.05$ \\
\hline $\mathrm{Cu}_{2} \mathrm{ZnSiSe}_{4}$ & $I \overline{4}$ & $1.82(\mathrm{D},--)$ & $0.98,0.98,0.10$ & $0.12,0.14,0.14$ & $-0.18 \pm 0.02$ \\
\hline $\mathrm{Cu}_{2} \mathrm{BeSiSe}_{4}$ & $I \overline{4}$ & $2.44(\mathrm{D},--)$ & $0.13, \mathrm{H}, \mathrm{H}$ & $0.23,0.23,0.17$ & $-0.34 \pm 0.07$ \\
\hline
\end{tabular}

The indirect way of studying defects mentioned above has one big advantage. Usually, the defect calculations require large supercell with hundreds of atoms with defects having different charge states. The systems we are interested in can have 400-700 atoms in the unit cell. Therefore, doing these calculations accurately on many systems with different kinds of defects is quite demanding. The indirect route we take to some extent serves the dual purpose of charge carrier mobility and the defect tolerance with relatively low computational cost. However, the presence of defects may affect the properties of materials in many other ways, for example, having their effect on intrinsic charge carrier concentration. In order to study these effects, one might consider doing the defect calculations in a systematic way, for example as described in Ref. [55].

Following the approach described above, a list of potential LBG candidates for tandem devices is provided in Tables Ia-Id. The tables contain all the materials which have the band gap in the required range of $1.5-2.5 \mathrm{eV}$. The compounds having at least two effective masses smaller than $0.5 m_{e}^{*}$ are written in bold. If the absolute value of the effective mass in a particular direction exceeds $3 m_{e}^{*}$, then the effective mass in that direction is termed as heavy $(H)$. As can be seen from the tables, only a handful of compounds meet the criteria of the effective masses on top of having the required band gap and thermodynamic stability. The list of candidates also contains $\mathrm{Cu}_{2} \mathrm{BaSnS}_{4}$ in the $P 3_{1}$ phase which has been shown to be a promising candidate for PEC devices [34]. Another important observation is that a large fraction of the compounds appear in the $P 3_{1}$ crystal structure, which is different from the most widely studied crystal structures of the $A_{2} B C X_{4}$ class of compounds, i.e., $I \overline{4}$ and $I \overline{4} 2 \mathrm{~m}$.

As a result of the screening process, a list of SBG materials is also obtained as shown in Tables IIa-IIb. The only difference in the selection of the LBG and SBG candidates is the range of the band gap which is $0.5-1.5 \mathrm{eV}$ in the case of SBG materials. Interestingly, the calculated effective masses of CZTS, which agree very well with past studies [56], do not fulfill the criterion we impose on the value of the effective mass. In the case of CZTS, it has been established that the defects are detrimental for its performance and careful measures are taken to avoid them [57]. So, this is in fact in accordance with the qualitative argument relating the defect tolerance and 
TABLE Ic. List of materials with $\mathrm{Ag}_{2} \mathrm{BCS}_{4}$ stoichiometry.

\begin{tabular}{|c|c|c|c|c|c|}
\hline Formula & Phase & $E_{g}\left(\right.$ type,$\left.E_{g}^{\mathrm{D}}-E_{g}^{\mathrm{I}}\right)$ & $m_{h}^{*}$ & $m_{e}^{*}$ & $E_{\text {hull }}$ \\
\hline $\mathrm{Ag}_{2} \mathrm{CsVS}_{4}$ & Ama2 & 1.77 (I, 0.13) & $\mathrm{H}, \mathrm{H}, 0.70$ & $\mathrm{H}, \mathrm{H}, 2.91$ & $-0.40 \pm 0.09$ \\
\hline $\mathrm{Ag}_{2} \mathrm{CdTiS}_{4}$ & $I \overline{4}$ & $1.96(\mathrm{I}, 0.41)$ & $\mathrm{H}, 0.90,0.87$ & $1.40,1.40,0.46$ & $-0.09 \pm 0.13$ \\
\hline $\mathrm{Ag}_{2} \mathrm{CdTiS}_{4}$ & $\operatorname{Pmn} 2_{1}$ & $2.28(\mathrm{I}, 0.13)$ & $\mathrm{H}, 1.36, \mathrm{H}$ & $\mathrm{H}, \mathrm{H}, \mathrm{H}$ & $-0.09 \pm 0.13$ \\
\hline $\mathrm{Ag}_{2} \mathrm{CdTiS}_{4}$ & $P 1 n 1$ & $2.28(\mathrm{I}, 0.13)$ & $\mathrm{H}, 1.35, \mathrm{H}$ & $\mathrm{H}, \mathrm{H}, \mathrm{H}$ & $-0.09 \pm 0.12$ \\
\hline $\mathrm{Ag}_{2} \mathrm{CaSnS}_{4}$ & $P \ln 1$ & $2.49(\mathrm{D},--)$ & $0.33,1.10, \mathrm{H}$ & $0.28,0.24,0.30$ & $-0.03 \pm 0.10$ \\
\hline $\mathrm{Ag}_{2} \mathrm{CaSnS}_{4}$ & $P m n 2_{1}$ & $2.49(\mathrm{D},--)$ & $0.35,1.05, \mathrm{H}$ & $0.28,0.30,0.24$ & $-0.03 \pm 0.10$ \\
\hline $\mathrm{Ag}_{2} \mathrm{CaSnS}_{4}$ & $I \overline{4} 2 m$ & $2.36(\mathrm{D},--)$ & $0.21, \mathrm{H}, \mathrm{H}$ & $0.24,0.30,0.30$ & $-0.03 \pm 0.10$ \\
\hline $\mathrm{Ag}_{2} \mathrm{CaSnS}_{4}$ & $I \overline{4}$ & $2.34(\mathrm{D},--)$ & $0.64, \mathrm{H}, \mathrm{H}$ & $0.28,0.28,0.26$ & $-0.02 \pm 0.10$ \\
\hline $\mathrm{Ag}_{2} \mathrm{CaSnS}_{4}$ & $P 3_{1}$ & $2.29(\mathrm{D},--)$ & $0.51,0.51, \mathrm{H}$ & $0.29,0.23,0.23$ & $-0.00 \pm 0.08$ \\
\hline $\mathrm{Ag}_{2} \mathrm{ZnTiS}_{4}$ & $I \overline{4}$ & $1.93(\mathrm{I}, 0.35)$ & $1.39,1.06,0.99$ & $0.48,1.29,1.29$ & $-0.08 \pm 0.12$ \\
\hline $\mathrm{Ag}_{2} \mathrm{ZnTiS}_{4}$ & $P m n 2_{1}$ & $2.23(\mathrm{I}, 0.12)$ & $\mathrm{H}, 2.02, \mathrm{H}$ & $\mathrm{H}, 1.10,2.50$ & $-0.08 \pm 0.12$ \\
\hline $\mathrm{Ag}_{2} \mathrm{ZnTiS}_{4}$ & $P 1 n 1$ & $2.23(\mathrm{I}, 0.12)$ & H, H, 2.02 & $\mathrm{H}, 2.52,1.13$ & $-0.08 \pm 0.12$ \\
\hline $\mathrm{Ag}_{2} \mathrm{MgSnS}_{4}$ & $I \overline{4}$ & $1.98(\mathrm{D},--)$ & $1.52,1.52,0.14$ & $0.20,0.27,0.27$ & $-0.09 \pm 0.12$ \\
\hline $\mathrm{Ag}_{2} \mathrm{MgSnS}_{4}$ & $P 1 n 1$ & $1.88(\mathrm{D},--)$ & $0.48, \mathrm{H},-1.80$ & $0.32,0.19,0.25$ & $-0.08 \pm 0.12$ \\
\hline $\mathrm{Ag}_{2} \mathrm{MgSnS}_{4}$ & $P m n 2_{1}$ & $1.88(\mathrm{D},--)$ & $0.48,1.81, \mathrm{H}$ & $0.32,0.25,0.19$ & $-0.08 \pm 0.12$ \\
\hline $\mathrm{Ag}_{2} \mathrm{MgGeS}_{4}$ & $I \overline{4}$ & $2.50(\mathrm{D},--)$ & H, H, 0.24 & $0.29,0.29,0.22$ & $-0.08 \pm 0.12$ \\
\hline $\mathrm{Ag}_{2} \mathrm{MgGeS}_{4}$ & $P m n 2_{1}$ & $2.30(\mathrm{D},--)$ & $0.60, \mathrm{H}, 1.67$ & $0.33,0.22,0.28$ & $-0.07 \pm 0.12$ \\
\hline $\mathrm{Ag}_{2} \mathrm{MgGeS}_{4}$ & $P 1 n 1$ & $2.30(\mathrm{D},--)$ & $0.61, \mathrm{H}, 1.67$ & $0.33,0.22,0.28$ & $-0.07 \pm 0.12$ \\
\hline $\mathrm{Ag}_{2} \mathrm{CdGeS}_{4}{ }^{4}$ & $I \overline{4}$ & $1.78(\mathrm{D},--)$ & $\mathrm{H}, \mathrm{H}, 0.24$ & $0.20,0.20,0.15$ & $-0.08 \pm 0.10$ \\
\hline $\mathrm{Ag}_{2} \mathrm{CdGeS}_{4}$ & $P m n 2_{1}$ & $1.60(\mathrm{D},--)$ & $0.24, \mathrm{H}, 1.37$ & $0.28,0.15,0.17$ & $-0.07 \pm 0.10$ \\
\hline $\mathrm{Ag}_{2} \mathrm{CdGeS}_{4}$ & $P 1 n 1$ & $1.60(\mathrm{D},--)$ & $0.24,1.36, \mathrm{H}$ & $0.28,0.17,0.15$ & $-0.08 \pm 0.10$ \\
\hline $\mathrm{Ag}_{2} \mathrm{ZnGeS}_{4}$ & $I \overline{4}$ & $1.95(\mathrm{D},--)$ & $2.07,2.07,0.16$ & $0.25,0.25,0.16$ & $-0.08 \pm 0.10$ \\
\hline $\mathrm{Ag}_{2} \mathrm{BeSnS}_{4}$ & $I \overline{4}$ & $2.09(\mathrm{D},--)$ & $0.19, \mathrm{H}, \mathrm{H}$ & $0.30,0.30,0.20$ & $-0.32 \pm 0.12$ \\
\hline
\end{tabular}

TABLE Id. List of materials with $\mathrm{Ag}_{2} B C \mathrm{Se}_{4}$ stoichiometry.

\begin{tabular}{|c|c|c|c|c|c|}
\hline Formula & Phase & $E_{g}\left(\right.$ type, $\left.E_{g}^{\mathrm{D}}-E_{g}^{\mathrm{I}}\right)$ & $m_{h}^{*}$ & $m_{e}^{*}$ & $E_{\text {hull }}$ \\
\hline $\mathrm{Ag}_{2} \mathrm{CsVSe}_{4}$ & $A m a 2$ & $1.45(\mathrm{I}, 0.07)$ & $\mathrm{H}, 0.58,1.64$ & H, H, 2.09 & $-0.36 \pm 0.07$ \\
\hline $\mathrm{Ag}_{2} \mathrm{KNbSe}_{4}$ & Ama2 & $2.46(\mathrm{I}, 0.01)$ & $\mathrm{H}, 1.76,1.60$ & $2.96,1.72,1.45$ & $-0.11 \pm 0.07$ \\
\hline $\mathrm{Ag}_{2} \mathrm{MgTiSe}_{4}$ & $I \overline{4}$ & $2.00(\mathrm{I}, 0.31)$ & $0.84,1.52,1.02$ & $1.38,1.38, \mathrm{H}$ & $-0.70 \pm 0.13$ \\
\hline $\mathrm{Ag}_{2} \mathrm{MgTiSe}_{4}$ & $P 1 n 1$ & $2.15(\mathrm{I}, 0.15)$ & $0.38, \mathrm{H}, \mathrm{H}$ & $H, 1.58,2.65$ & $-0.70 \pm 0.12$ \\
\hline $\mathrm{Ag}_{2} \mathrm{MgTiSe}_{4}$ & $\operatorname{Pmn} 2_{1}$ & $2.14(\mathrm{I}, 0.16)$ & $0.37, \mathrm{H}, \mathrm{H}$ & $\mathrm{H}, 2.31,2.31$ & $-0.70 \pm 0.12$ \\
\hline $\mathrm{Ag}_{2} \mathrm{CdTiSe}_{4}$ & $I \overline{4}$ & 1.59 (I, 0.37) & $0.79,1.01,0.92$ & $1.16,1.16,0.42$ & $-0.42 \pm 0.11$ \\
\hline $\mathrm{Ag}_{2} \mathrm{CdTiSe}_{4}$ & $P 1 n 1$ & $1.86(\mathrm{I}, 0.08)$ & $0.36, \mathrm{H}, \mathrm{H}$ & $\mathrm{H}, 0.71, \mathrm{H}$ & $-0.41 \pm 0.11$ \\
\hline $\mathrm{Ag}_{2} \mathrm{CdTiSe}_{4}$ & $\operatorname{Pmn} 2_{1}$ & $1.85(\mathrm{I}, 0.09)$ & $0.36, \mathrm{H}, \mathrm{H}$ & $\mathrm{H}, 0.72, \mathrm{H}$ & $-0.41 \pm 0.11$ \\
\hline $\mathrm{Ag}_{2} \mathrm{CdTiSe}_{4}$ & $A m a 2$ & $2.03(\mathrm{I}, 0.06)$ & $\mathrm{H}, 2.81,0.34$ & $2.37,1.23,0.76$ & $-0.36 \pm 0.06$ \\
\hline $\mathrm{Ag}_{2} \mathrm{CaSnSe}_{4}$ & $I \overline{4} 2 m$ & $1.60(\mathrm{D},--)$ & H, H, 0.12 & $0.14,0.25,0.25$ & $-0.08 \pm 0.10$ \\
\hline $\mathrm{Ag}_{2} \mathrm{CaSnSe}_{4}$ & $P m n 2_{1}$ & $1.67(\mathrm{D},--)$ & $\mathrm{H}, 0.16,1.99$ & $0.25,0.15,0.22$ & $-0.08 \pm 0.09$ \\
\hline $\mathrm{Ag}_{2} \mathrm{CaSnSe}_{4}$ & $P 1 n 1$ & $1.67(\mathrm{D},--)$ & $\mathrm{H}, 0.16,1.85$ & $0.25,0.15,0.22$ & $-0.08 \pm 009$ \\
\hline $\mathrm{Ag}_{2} \mathrm{CaSnSe}_{4}$ & $P 3_{1}$ & $1.54(\mathrm{D},--)$ & $\mathrm{H}, 0.27,0.27$ & $0.24,0.17,0.17$ & $-0.04 \pm 0.08$ \\
\hline $\mathrm{Ag}_{2} \mathrm{ZnTiSe}_{4}$ & $I \overline{4}$ & 1.59 (I, 0.34) & $1.37,0.91,0.86$ & $1.07,1.07,0.44$ & $-0.41 \pm 0.11$ \\
\hline $\mathrm{Ag}_{2} \mathrm{ZnTiSe}_{4}$ & $P 1 n 1$ & 1.80 (I, 0.09) & $0.42, \mathrm{H}, \mathrm{H}$ & $\mathrm{H}, 1.10,2.07$ & $-0.40 \pm 0.11$ \\
\hline $\mathrm{Ag}_{2} \mathrm{ZnTiSe}_{4}$ & $\operatorname{Pmn} 2_{1}$ & $1.79(\mathrm{I}, 0.10)$ & $0.43, \mathrm{H}, \mathrm{H}$ & $\mathrm{H}, 2.07,1.10$ & $-0.40 \pm 0.11$ \\
\hline $\mathrm{Ag}_{2} \mathrm{ZnTiSe}_{4}$ & $A m a 2$ & $1.93(\mathrm{D},--)$ & $1.82, \mathrm{H}, \mathrm{H}$ & $1.00,2.18,0.48$ & $-0.36 \pm 0.06$ \\
\hline $\mathrm{Ag}_{2} \mathrm{CaGeSe}_{4}$ & $P 1 n 1$ & $1.85(\mathrm{D},--)$ & $\mathrm{H}, 0.15, \mathrm{H}$ & $0.37,0.15,0.22$ & $+0.00 \pm 0.07$ \\
\hline $\mathrm{Ag}_{2} \mathrm{CaGeSe}_{4}$ & $I \overline{4} 2 m$ & $1.75(\mathrm{I}, 0.04)$ & $0.82,0.82, \mathrm{H}$ & $0.14,0.28,0.28$ & $+0.00 \pm 0.07$ \\
\hline $\mathrm{Ag}_{2} \mathrm{CaGeSe}_{4}$ & $P m n 2_{1}$ & $1.83(\mathrm{D},--)$ & $\mathrm{H}, 0.14, \mathrm{H}$ & $0.38,0.22,0.15$ & $+0.00 \pm 0.07$ \\
\hline $\mathrm{Ag}_{2} \mathrm{CaGeSe}_{4}$ & $P 3_{1}$ & $1.85(\mathrm{D},--)$ & $1.81,0.24,0.24$ & $0.22,0.18,0.18$ & $+0.03 \pm 0.06$ \\
\hline $\mathrm{Ag}_{2} \mathrm{BeTiSe}_{4}$ & $I \overline{4}$ & $1.88(\mathrm{I}, 0.35)$ & $\mathrm{H}, 1.31,0.95$ & $0.70,1.45,1.45$ & $-0.62 \pm 0.12$ \\
\hline $\mathrm{Ag}_{2} \mathrm{MgSiSe}_{4}$ & $I \overline{4}$ & $2.42(\mathrm{I}, 0.01)$ & $1.78,0.58,0.58$ & $0.18,0.18,0.17$ & $-0.50 \pm 0.10$ \\
\hline $\mathrm{Ag}_{2} \mathrm{MgSiSe}_{4}$ & $\operatorname{Pmn} 2_{1}$ & $2.15(\mathrm{D},--)$ & $0.33,0.94, \mathrm{H}$ & $0.18,0.26,0.15$ & $-0.49 \pm 0.10$ \\
\hline $\mathrm{Ag}_{2} \mathrm{MgSiSe}_{4}$ & $P 1 n 1$ & $2.15(\mathrm{D},--)$ & $0.33,0.94, \mathrm{H}$ & $0.18,0.15,0.26$ & $-0.49 \pm 0.10$ \\
\hline $\mathrm{Ag}_{2} \mathrm{ZnSiSe}_{4}$ & $I \overline{4}$ & $1.83(\mathrm{D},--)$ & H, H, 0.10 & $0.18,0.18,0.11$ & $-0.21 \pm 0.09$ \\
\hline
\end{tabular}


TABLE IIa. List of materials with $\mathrm{Cu}_{2} B C X_{4}$ stoichiometry. The listed materials are below the convex hull, and have the band gap in the desired range of $0.5-1.5 \mathrm{eV}$ for single-junction PV devices. The materials which fulfill the criterion that at least two of the effective masses for both electrons and holes are smaller than 0.5 are indicated in bold. The electron and hole effective masses are denoted as $m_{e}^{*}$ and $m_{h}^{*}$, respectively. $E_{g}$ and $\Delta H_{\text {hull }}$ represent the band gap in $\mathrm{eV}$ and the energy with respect to the convex hull in $\mathrm{eV} /$ atom. The b part of the table is for materials with stoichiometry $\mathrm{Ag}_{2} \mathrm{BCX}_{4}$. Different compounds are separated with alternating gray and white colors.

\begin{tabular}{|c|c|c|c|c|c|}
\hline Formula & Phase & $E_{g}\left(\right.$ type, $\left.E_{g}^{\mathrm{D}}-E_{g}^{\mathrm{I}}\right)$ & $m_{h}^{*}$ & $m_{e}^{*}$ & $\Delta H_{\text {hull }}$ \\
\hline $\mathrm{Cu}_{2} \mathrm{CdSnS}_{4}$ & $I \overline{4} 2 m$ & $0.94(\mathrm{D},--)$ & H, H, 0.08 & $0.10,0.19,0.19$ & $-0.12 \pm 0.10$ \\
\hline $\mathrm{Cu}_{2} \mathrm{ZnSnS}_{4}$ & $I \overline{4}$ & $1.17(\mathrm{D},--)$ & $0.94,0.94,0.14$ & $0.14,0.17,0.17$ & $-0.12 \pm 0.10$ \\
\hline $\mathrm{Cu}_{2} \mathrm{KVSe}_{4}$ & $A m a 2$ & 1.41 (I, 0.01) & $\mathrm{H}, 1.20,2.38$ & $\mathrm{H}, 2.48,1.36$ & $-0.40 \pm 0.02$ \\
\hline $\mathrm{Cu}_{2} \mathrm{BaSnSe}_{4}$ & $P 3_{1}$ & $0.88(\mathrm{D},--)$ & $\mathrm{H}, 0.12,0.11$ & $0.32,0.09,0.09$ & $-0.11 \pm 0.04$ \\
\hline $\mathrm{Cu}_{2} \mathrm{BaGeSe}_{4}$ & $P 3_{1}$ & $1.31(\mathrm{D},--)$ & $\mathrm{H}, 0.15,0.15$ & $0.41,0.12,0.12$ & $-0.06 \pm 0.07$ \\
\hline $\mathrm{Cu}_{2} \mathrm{SrSnSe}_{4}$ & $P 3_{1}$ & $0.94(\mathrm{D},--)$ & $0.13,0.12, \mathrm{H}$ & $0.46,0.09,0.09$ & $-0.66 \pm 0.04$ \\
\hline $\mathrm{Cu}_{2} \mathrm{SrGeSe}_{4}$ & $P 3_{1}$ & $1.39(\mathrm{D},--)$ & $\mathrm{H}, 0.15,0.15$ & $0.51,0.11,0.11$ & $-0.60 \pm 0.04$ \\
\hline $\mathrm{Cu}_{2} \mathrm{CaSnSe}_{4}$ & $I \overline{4} 2 m$ & $1.46(\mathrm{I}, 0.02)$ & $0.82,0.88,0.41$ & $0.23,0.23,0.14$ & $-0.03 \pm 0.05$ \\
\hline $\mathrm{Cu}_{2} \mathrm{CaSnSe}_{4}$ & $P m n 2_{1}$ & $1.31(\mathrm{I}, 0.01)$ & $2.65,0.35,0.42$ & $0.20,0.13,0.30$ & $-0.03 \pm 0.05$ \\
\hline $\mathrm{Cu}_{2} \mathrm{CaSnSe}_{4}$ & $P \ln 1$ & $1.31(\mathrm{I}, 0.01)$ & $2.72,0.36,0.41$ & $0.20,0.13,0.30$ & $-0.03 \pm 0.05$ \\
\hline $\mathrm{Cu}_{2} \mathrm{CaSnSe}_{4}$ & $P 3_{1}$ & $1.06(\mathrm{D},--)$ & $0.16,0.15, \mathrm{H}$ & $0.48,0.14,0.14$ & $-0.01 \pm 0.02$ \\
\hline $\mathrm{Cu}_{2} \mathrm{MgSnSe}_{4}$ & $I \overline{4} 2 m$ & $0.85(\mathrm{D},--)$ & $0.08, \mathrm{H}, \mathrm{H}$ & $0.08,0.16,0.16$ & $-0.44 \pm 0.06$ \\
\hline $\mathrm{Cu}_{2} \mathrm{MgSnSe}_{4}$ & $I \overline{4}$ & $0.72(\mathrm{D},--)$ & $0.19,0.19,0.67$ & $0.10,0.10,0.08$ & $-0.44 \pm 0.06$ \\
\hline $\mathrm{Cu}_{2} \mathrm{MgGeSe}_{4}$ & $I \overline{4} 2 m$ & $1.11(\mathrm{D},--)$ & $1.08,1.08,0.12$ & $0.16,0.16,0.10$ & $-0.38 \pm 0.04$ \\
\hline $\mathrm{Cu}_{2} \mathrm{MgGeSe}_{4}$ & $\operatorname{Pmn} 2_{1}$ & $1.22(\mathrm{D},--)$ & $0.18,0.76,0.64$ & $0.20,0.21,0.11$ & $-0.37 \pm 0.03$ \\
\hline $\mathrm{Cu}_{2} \mathrm{MgGeSe}_{4}$ & $P 1 n 1$ & $1.22(\mathrm{D},--)$ & $0.18,0.75,0.64$ & $0.20,0.11,0.21$ & $-0.37 \pm 0.03$ \\
\hline $\mathrm{Cu}_{2} \mathrm{ZnGeSe}_{4}$ & $I \overline{4}$ & $0.59(\mathrm{D},--)$ & $0.47,0.47,0.05$ & $0.07,0.07,0.05$ & $-0.04 \pm 0.04$ \\
\hline $\mathrm{Cu}_{2} \mathrm{BeSnSe}_{4}$ & $I \overline{4}$ & $0.98(\mathrm{D},--)$ & $0.19,0.19,0.49$ & $0.12,0.15,0.15$ & $-0.30 \pm 0.06$ \\
\hline $\mathrm{Cu}_{2} \mathrm{BeGeSe}_{4}$ & $I \overline{4}$ & $1.10(\mathrm{I}, 0.05)$ & H, H, 0.08 & H, H, 0.42 & $-0.23 \pm 0.05$ \\
\hline
\end{tabular}

the effective masses. A few materials qualify all the criteria we impose and, similar to the LBG list, the list of SBG materials is dominated by the $P 3_{1}$ structure. Similar to $\mathrm{Cu}_{2} \mathrm{BaSnS}_{4}$, the selenides in this class turn out to be suitable as SBG light absorbers. A few other compounds also satisfy all the criteria, for example, $\mathrm{Cu}_{2} \mathrm{MgSnSe}_{4}, \mathrm{Cu}_{2} \mathrm{BeSnSe}_{4}, \mathrm{Ag}_{2} \mathrm{MgGeSe}_{4}$, and $\mathrm{Ag}_{2} \mathrm{BeGeSe}_{4}$. The materials $\mathrm{Cu}_{2} \mathrm{CaSnSe}_{4}, \mathrm{Cu}_{2} \mathrm{ZnGeSe}_{4}$, and $\mathrm{Ag}_{2} \mathrm{CdGeSe}_{4}$ appearing in the list seem to be on the verge of

TABLE IIb. List of materials with $\mathrm{Ag}_{2} B C X_{4}$ stoichiometry.

\begin{tabular}{|c|c|c|c|c|c|}
\hline Formula & Phase & $E_{g}\left(\right.$ type, $\left.E_{g}^{\mathrm{D}}-E_{g}^{\mathrm{I}}\right)$ & $m_{h}^{*}$ & $m_{e}^{*}$ & $E_{\text {hull }}$ \\
\hline $\mathrm{Ag}_{2} \mathrm{CdSnS}_{4}$ & $I \overline{4}$ & $1.28(\mathrm{D},--)$ & $\mathrm{H}, \mathrm{H}, 0.11$ & $0.13,0.18,0.18$ & $-0.08 \pm 0.10$ \\
\hline $\mathrm{Ag}_{2} \mathrm{CdSnS}_{4}$ & $P m n 2_{1}$ & $1.23(\mathrm{D},--)$ & $0.21,1.54, \mathrm{H}$ & $0.06,0.09,0.08$ & $-0.08 \pm 0.10$ \\
\hline $\mathrm{Ag}_{2} \mathrm{CdSnS}_{4}$ & $P 1 n 1$ & $1.23(\mathrm{D},--)$ & $0.21,1.54, \mathrm{H}$ & $0.25,0.12,0.15$ & $-0.08 \pm 0.10$ \\
\hline $\mathrm{Ag}_{2} \mathrm{ZnSnS}_{4}$ & $I \overline{4}$ & $1.44(\mathrm{D},--)$ & $1.48,1.48,0.11$ & $0.23,0.23,0.13$ & $-0.08 \pm 0.10$ \\
\hline $\mathrm{Ag}_{2} \mathrm{RbVSe}_{4}$ & $A m a 2$ & $1.38(\mathrm{I}, 0.02)$ & $2.00,0.72,1.35$ & H, H, 1.74 & $-0.35 \pm 0.06$ \\
\hline $\mathrm{Ag}_{2} \mathrm{KVSe}_{4}$ & $A m a 2$ & $1.32(\mathrm{D},--)$ & $0.81,1.71,2.04$ & $\mathrm{H}, \mathrm{H}, 1.57$ & $-0.33 \pm 0.06$ \\
\hline $\mathrm{Ag}_{2} \mathrm{NaVSe}_{4}$ & $P m n 2_{1}$ & $0.87(\mathrm{I}, 0.32)$ & $0.99,0.74,1.40$ & $0.93,0.83,1.83$ & $-0.29 \pm 0.09$ \\
\hline $\mathrm{Ag}_{2} \mathrm{NaVSe}_{4}$ & $P 1 n 1$ & $0.87(\mathrm{I}, 0.32)$ & $0.99,0.74,1.40$ & $0.93,0.83,1.85$ & $-0.29 \pm 0.09$ \\
\hline $\mathrm{Ag}_{2} \mathrm{NaVSe}_{4}$ & Ama2 & $1.13(\mathrm{I}, 0.01)$ & $0.49,0.74,1.43$ & 1.40, H, 2.36 & $-0.27 \pm 0.09$ \\
\hline $\mathrm{Ag}_{2} \mathrm{LiVSe}_{4}$ & $P 1 n 1$ & 0.98 (I, 0.34) & $0.84,0.84,1.52$ & $1.75,2.27,2.41$ & $-0.28 \pm 0.11$ \\
\hline $\mathrm{Ag}_{2} \mathrm{LiVSe}_{4}$ & $I \overline{4} 2 m$ & 0.50 (I, 0.34) & $0.41,0.93,1.30$ & $0.33,0.94,0.94$ & $-0.28 \pm 0.11$ \\
\hline $\mathrm{Ag}_{2} \mathrm{LiVSe}_{4}$ & $I \overline{4}$ & $0.70(\mathrm{I}, 0.52)$ & $\mathrm{H}, 0.81,0.74$ & $1.44,1.44, \mathrm{H}$ & $-0.28 \pm 0.12$ \\
\hline $\mathrm{Ag}_{2} \mathrm{LiVSe}_{4}$ & $A m a 2$ & $1.31(\mathrm{D},--)$ & $0.85,1.22, \mathrm{H}$ & H, H, 2.04 & $-0.25 \pm 0.07$ \\
\hline $\mathrm{Ag}_{2} \mathrm{MgSnSe}_{4}$ & $I \overline{4}$ & $1.11(\mathrm{D},--)$ & $0.08, \mathrm{H}, \mathrm{H}$ & $0.13,0.13,0.10$ & $-0.42 \pm 0.11$ \\
\hline $\mathrm{Ag}_{2} \mathrm{MgGeSe}_{4}$ & $I \overline{4}$ & $1.34(\mathrm{D},--)$ & $0.09, \mathrm{H}, \mathrm{H}$ & $0.15,0.15,0.12$ & $-0.33 \pm 0.08$ \\
\hline $\mathrm{Ag}_{2} \mathrm{MgGeSe}_{4}$ & $P 1 n 1$ & $1.16(\mathrm{D},--)$ & $0.17,0.73, \mathrm{H}$ & $0.13,0.12,0.21$ & $-0.32 \pm 0.08$ \\
\hline $\mathrm{Ag}_{2} \mathrm{MgGeSe}_{4}$ & $P m n 2_{1}$ & $1.16(\mathrm{D},--)$ & $0.17,0.73, \mathrm{H}$ & $0.13,0.12,0.21$ & $-0.32 \pm 0.08$ \\
\hline $\mathrm{Ag}_{2} \mathrm{CdGeSe}_{4}$ & $I \overline{4}$ & $0.69(\mathrm{D},--)$ & $0.36,0.36,0.57$ & $0.12,0.12,0.05$ & $-0.04 \pm 0.07$ \\
\hline $\mathrm{Ag}_{2} \mathrm{CdGeSe}_{4}$ & $P m n 2_{1}$ & $0.50(\mathrm{D},--)$ & $0.09,0.35,0.88$ & $0.07,0.11,0.06$ & $-0.04 \pm 0.07$ \\
\hline $\mathrm{Ag}_{2} \mathrm{CdGeSe}_{4}$ & $P 1 n 1$ & $0.50(\mathrm{D},--)$ & $0.09,0.89,0.35$ & $0.07,0.06,0.11$ & $-0.04 \pm 0.07$ \\
\hline $\mathrm{Ag}_{2} \mathrm{ZnSnSe}_{4}$ & $I \overline{4}$ & $0.56(\mathrm{D},--)$ & H, H, 0.03 & $0.11,0.11,0.04$ & $-0.13 \pm 0.09$ \\
\hline $\mathrm{Ag}_{2} \mathrm{ZnGeSe}_{4}$ & $I \overline{4}$ & $0.76(\mathrm{D},--)$ & $0.04, \mathrm{H}, \mathrm{H}$ & $0.16,0.16,0.05$ & $-0.04 \pm 0.07$ \\
\hline $\mathrm{Ag}_{2} \mathrm{BeSnSe}_{4}$ & $I \overline{4}$ & $1.21(\mathrm{D},--)$ & $0.41,0.87,1.15$ & $0.12,0.12,0.11$ & $-0.34 \pm 0.11$ \\
\hline $\mathrm{Ag}_{2} \mathrm{BeGeSe}_{4}$ & $I \overline{4}$ & $1.39(\mathrm{D},--)$ & $0.80,0.39,0.19$ & $0.11,0.15,0.15$ & $-0.26 \pm 0.09$ \\
\hline
\end{tabular}


TABLE III. The calculated band edge positions (in volts) using 1 of the LBG candidates written in bold in Tables Ia-Id. The values are with respect to the normal hydrogen electrode (NHE).

\begin{tabular}{lccc}
\hline \hline Compound & Phase & VBM & CBM \\
\hline $\mathrm{Cu}_{2} \mathrm{BaSiSe}_{4}$ & $P 3_{1}$ & 1.56 & -0.86 \\
$\mathrm{Ag}_{2} \mathrm{CaSnSe}_{4}$ & $P 3_{1}$ & 0.94 & -0.60 \\
$\mathrm{Cu}_{2} \mathrm{CaSnS}_{4}$ & $P 3_{1}$ & 1.13 & -0.51 \\
$\mathrm{Ag}_{2} \mathrm{CaGeSe}_{4}$ & $P 3_{1}$ & 1.13 & -0.72 \\
$\mathrm{Cu}_{2} \mathrm{SrGeS}_{4}$ & $P 3_{1}$ & 1.50 & -0.92 \\
$\mathrm{Cu}_{2} \mathrm{SrSnS}_{4}$ & $P 3_{1}$ & 1.04 & -0.54 \\
$\mathrm{Cu}_{2} \mathrm{BaGeS}_{4}$ & $P 3_{1}$ & 1.62 & -0.68 \\
$\mathrm{Cu}_{2} \mathrm{CaGeSe}_{4}$ & $P 3_{1}$ & 0.97 & -0.54 \\
$\mathrm{Cu}_{2} \mathrm{BaSnS}_{4}$ & $P 3_{1}$ & 1.19 & -0.34 \\
\hline \hline
\end{tabular}

instability (heat of formation close to zero) and may not be stable under normal conditions.

Finally, we report the band edge positions based on the empirical equation (1) for the LBG candidates written in bold in Tables Ia-Id. Depending on the device architecture the LBG semiconductor can be the front or the back absorber and silicon is used as a standard SBG component. The VBM of the LBG semiconductor in this case has to be $>1.5 \mathrm{~V}$ or so relative to normal hydrogen electrode [16]. Also, employing the $p-n$ junction can tune the band alignment to make it appropriate if they are not too off. As Table III shows, almost all the LBG candidates have the VBM in the same ballpark except $\mathrm{Ag}_{2} \mathrm{CaSnSe}_{4}$ and $\mathrm{Cu}_{2} \mathrm{CaGeSe}_{4}$ which are a bit too small. However, as mentioned earlier, there is a certain degree of uncertainty in using the empirical approach to calculate the band edge. However, the values reported in Table III serve as a reasonable estimate and can be potentially useful in experimental assessment of the candidates.

\section{CONCLUSION}

In this work, we have focused on identifying light absorbers for tandem PEC devices in the quaternary chalcogenide class with stoichiometry $A_{2} B C X_{4}$. The crystal structures explored are not limited to only the most studied $I \overline{4}$ and $I \overline{4} 2 m$ crystal structures of CZTS. In total, 228 compounds are explored in 6 different crystal structures. In general, we find that the thermodynamic and optical properties vary significantly for a given compound in the different crystal structures. Employing the criteria of the band gap being in the range of $1.5-2.5 \mathrm{eV}$, thermodynamic stability, and low charge carrier effective masses in at least two directions, we find less than 10 materials fulfilling all the criteria as promising light absorbers for tandem PEC devices. In the short list, we also find the recently investigated $\mathrm{Cu}_{2} \mathrm{BaSnS}_{4}$ for PEC applications which consolidates the approach. Based on the qualitative correlation between effective masses and defect tolerance, all the promising candidates might be defect tolerant.

\section{ACKNOWLEDGMENT}

This work was supported by a research grant (Grant No. 9455) from VILLUM FONDEN.
[1] A. Fujishima and K. Honda, Nature (London) 238, 37 (1972).

[2] A. M. Kolpak and J. C. Grossman, Nano Lett. 11, 3156 (2011).

[3] Q. Guo, G. M. Ford, W.-C. Yang, B. C. Walker, E. A. Stach, H. W. Hillhouse, and R. Agrawal, J. Am. Chem. Soc. 132, 17384 (2010).

[4] H. Katagiri, K. Jimbo, W. S. Maw, K. Oishi, M. Yamazaki, H. Araki, and A. Takeuchi, Thin Solid Films 517, 2455 (2009).

[5] O. Khaselev and J. A. Turner, Science 280, 425 (1998).

[6] K. Kuhar, M. Pandey, K. S. Thygesen, and K. W. Jacobsen, ACS Energy Lett. 3, 436 (2018).

[7] M. A. Green, Prog. Photovoltaics 17, 183 (2009).

[8] W. S. Yang, B.-W. Park, E. H. Jung, N. J. Jeon, Y. C. Kim, D. U. Lee, S. S. Shin, J. Seo, E. K. Kim, J. H. Noh, and S. I. Seok, Science 356, 1376 (2017).

[9] M. Saliba, T. Matsui, K. Domanski, J.-Y. Seo, A. Ummadisingu, S. M. Zakeeruddin, J.-P. Correa-Baena, W. R. Tress, A. Abate, A. Hagfeldt et al., Science 354, 206 (2016).

[10] P. C. K. Vesborg and B. Seger, Chem. Mater. 28, 8844 (2016).

[11] S. Hu, C. Xiang, S. Haussener, A. D. Berger, and N. S. Lewis, Energy Environ. Sci. 6, 2984 (2013).

[12] M. F. Weber and M. J. Dignam, Int. J. Hydrogen Energy 11, 225 (1986).

[13] J. Y. Kim, G. Magesh, D. H. Youn, J.-W. Jang, J. Kubota, K. Domen, and J. S. Lee, Sci. Rep. 3, 2681 (2013).

[14] M. Dumortier, S. Tembhurne, and S. Haussener, Energy Environ. Sci. 8, 3614 (2015).
[15] B. Seger, O. Hansen, and P. C. K. Vesborg, Solar RRL 1, e201600013 (2017).

[16] B. Seger, I. E. Castelli, P. C. K. Vesborg, K. W. Jacobsen, O. Hansen, and I. Chorkendorff, Energy Environ. Sci. 7, 2397 (2014).

[17] L. C. Seitz, Z. Chen, A. J. Forman, B. A. Pinaud, J. D. Benck, and T. F. Jaramillo, Chemsuschem 7, 1372 (2014).

[18] R. E. Rocheleau and E. L. Miller, Int. J. Hydrogen Energy 22, 771 (1997).

[19] M. R. Shaner, K. T. Fountaine, S. Ardo, R. H. Coridan, H. A. Atwater, and N. S. Lewis, Energy Environ. Sci. 7, 779 (2014).

[20] A. Paracchino, V. Laporte, K. Sivula, M. Gratzel, and E. Thimsen, Nat. Mater. 10, 456 (2011).

[21] L. Han, F. F. Abdi, R. van de Krol, R. Liu, Z. Huang, H.-J. Lewerenz, B. Dam, M. Zeman, and A. H. M. Smets, Chemsuschem 7, 2832 (2014).

[22] K. Sivula, F. Le Formal, and M. Gratzel, Chemsuschem 4, 432 (2011).

[23] H. Katagiri, K. Jimbo, M. Tahara, H. Araki, and K. Oishi, MRS Proc. 1165, 1165-M04-01 (2009).

[24] H. Zhou, W.-C. Hsu, H.-S. Duan, B. Bob, W. Yang, T.-B. Song, C.-J. Hsu, and Y. Yang, Energy Environ. Sci. 6, 2822 (2013).

[25] B. Shin, O. Gunawan, Y. Zhu, N. A. Bojarczuk, S. J. Chey, and S. Guha, Prog. Photovoltaics 21, 72 (2013).

[26] Q. Guo, H. W. Hillhouse, and R. Agrawal, J. Am. Chem. Soc. 131, 11672 (2009). 
[27] W. Wang, M. T. Winkler, O. Gunawan, T. Gokmen, T. K. Todorov, Y. Zhu, and D. B. Mitzi, Adv. Ener. Mater. 4, 1301465 (2014).

[28] Q. Guo, G. M. Ford, W.-C. Yang, C. J. Hages, H. W. Hillhouse, and R. Agrawal, Sol. Energy Mater. Sol. Cells 105, 132 (2012).

[29] T. K. Todorov, J. Tang, S. Bag, O. Gunawan, T. Gokmen, Y. Zhu, and D. B. Mitzi, Adv. Ener. Mater. 3, 34 (2013).

[30] S. Chen, A. Walsh, J.-H. Yang, X. G. Gong, L. Sun, P.-X. Yang, J.-H. Chu, and S.-H. Wei, Phys. Rev. B 83, 125201 (2011).

[31] Y. Cao, M. S. Denny, J. V. Caspar, W. E. Farneth, Q. Guo, A. S. Ionkin, L. K. Johnson, M. Lu, I. Malajovich, D. Radu, H. D. Rosenfeld, K. R. Choudhury, and W. Wu, J. Am. Chem. Soc. 134, 15644 (2012).

[32] A. Walsh, S. Chen, S.-H. Wei, and X.-G. Gong, Adv. Energy Mater. 2, 400 (2012).

[33] D. Shin, E. Ngaboyamahina, Y. Zhou, J. T. Glass, and D. B. Mitzi, J. Phys. Chem. Lett. 7, 4554 (2016).

[34] D. Shin, T. Zhu, X. Huang, O. Gunawan, V. Blum, and D. B. Mitzi, Adv. Mater. 29, 1606945 (2017).

[35] T. Gershon, K. Sardashti, O. Gunawan, R. Mankad, S. Singh, Y. S. Lee, J. A. Ott, A. Kummel, and R. Haight, Adv. Energy Mater. 6, 1601182 (2016).

[36] T. Gershon, Y. S. Lee, P. Antunez, R. Mankad, S. Singh, D. Bishop, O. Gunawan, M. Hopstaken, and R. Haight, Adv. Energy Mater. 6, 1502468 (2016).

[37] T. Zhu, W. P. Huhn, G. C. Wessler, D. Shin, B. Saparov, D. B. Mitzi, and V. Blum, Chem. Mater. 29, 7868 (2017).

[38] R. Chen and C. Persson, J. Appl. Phys. 121, 203104 (2017).

[39] G. Bergerhoff, R. Hundt, R. Sievers, and I. D. Brown, J. Chem. Inf. Comput. Sci. 23, 66 (1983).

[40] K. Kuhar, A. Crovetto, M. Pandey, K. S. Thygesen, B. Seger, P. C. K. Vesborg, O. Hansen, I. Chorkendorff, and K. W. Jacobsen, Energy Environ. Sci. 10, 2579 (2017).

[41] S. Yang, D. Prendergast, and J. B. Neaton, Nano Lett. 12, 383 (2012).

[42] M. Butler and D. Ginley, J. Electrochem. Soc. 125, 228 (1978).

[43] L.-J. Guo, J.-W. Luo, T. He, S.-H. Wei, and S.-S. Li, arXiv:1801.01334v2.

[44] C. Jiang, S. J. A. Moniz, A. Wang, T. Zhang, and J. Tang, Chem. Soc. Rev. 46, 4645 (2017).
[45] J. Enkovaara, C. Rostgaard, J. J. Mortensen, J. Chen, M. Dułak, L. Ferrighi, J. Gavnholt, C. Glinsvad, V. Haikola, H. A. Hansen et al., J. Phys.: Condens. Matter 22, 253202 (2010).

[46] A. H. Larsen, J. J. Mortensen, J. Blomqvist, I. E. Castelli, R. Christensen, M. Dułak, J. Friis, M. N. Groves, B. Hammer, C. Hargus, E. D. Hermes, P. C. Jennings, P. B. Jensen, J. Kermode, J. R. Kitchin, E. L. Kolsbjerg, J. Kubal, K. Kaasbjerg, S. Lysgaard, J. B. Maronsson et al., J. Phys.: Condens. Matter 29, 273002 (2017).

[47] J. P. Perdew, A. Ruzsinszky, G. I. Csonka, O. A. Vydrov, G. E. Scuseria, L. A. Constantin, X. Zhou, and K. Burke, Phys. Rev. Lett. 100, 136406 (2008).

[48] H. J. Monkhorst and J. D. Pack, Phys. Rev. B 13, 5188 (1976).

[49] J. Wellendorff, K. T. Lundgaard, K. W. Jacobsen, and T. Bligaard, J. Chem. Phys. 140, 144107 (2014).

[50] M. Pandey and K. W. Jacobsen, Phys. Rev. B 91, 235201 (2015).

[51] J. Ge, P. J. Roland, P. Koirala, W. Meng, J. L. Young, R. Petersen, T. G. Deutsch, G. Teeter, R. J. Ellingson, R. W. Collins, and Y. Yan, Chem. Mater. 29, 916 (2017).

[52] Similar plot as Fig. 5 for the other phases, and relative energies plots as Fig. 2 for different stoichiometries. The database containing structural informations, total energies, and the band gaps is available at the Computational Materials Repository webpage (https://cmr.fysik.dtu.dk/index.html) under the link https://cmrdb.fysik.dtu.dk/?project=a2bcx 4

[53] S. Ahn, S. Jung, J. Gwak, A. Cho, K. Shin, K. Yoon, D. Park, H. Cheong, and J. H. Yun, Appl. Phys. Lett. 97, 021905 (2010).

[54] A. Walsh and A. Zunger, Nat. Mater. 16, 964 (2017).

[55] J. Balachandran, L. Lin, J. S. Anchell, C. A. Bridges, and P. Ganesh, J. Phys. Chem. C 121, 26637 (2017).

[56] H.-R. Liu, S. Chen, Y.-T. Zhai, H. J. Xiang, X. G. Gong, and S.-H. Wei, J. Appl. Phys. 112, 093717 (2012).

[57] S. Chen, X. G. Gong, A. Walsh, and S.-H. Wei, Appl. Phys. Lett. 96, 021902 (2010).

[58] See Supplemental Material at http://link.aps.org/supplemental/ 10.1103/PhysRevMaterials.2.105402 for the trends in band gaps upon elemental substitution, and the relative energies of the different phases. 